\title{
A tailored multi-model ensemble for air traffic management: Demonstration and evaluation for the Eyjafjallajökull eruption in May 2010
}

\author{
Matthieu Plu ${ }^{1}$, Barbara Scherllin-Pirscher ${ }^{2}$, Delia Arnold Arias ${ }^{2}$, Rocio Baro ${ }^{2}$, Guillaume Bigeard $^{1}$, \\ Luca Bugliaro $^{3}$, Ana Carvalho ${ }^{4}$, Laaziz El Amraoui ${ }^{1}$, Kurt Eschbacher ${ }^{5}$, Marcus Hirtl ${ }^{2}$, \\ Christian Maurer ${ }^{2}$, Marie D. Mulder ${ }^{2}$, Dennis Piontek ${ }^{3}$, Lennart Robertson ${ }^{4}$, Carl-Herbert Rokitansky ${ }^{5}$, \\ Fritz Zobl ${ }^{5}$, and Raimund Zopp ${ }^{6}$ \\ ${ }^{1}$ CNRM, Université de Toulouse, Météo-France, CNRS, Toulouse, France \\ ${ }^{2}$ Zentralanstalt für Meteorologie und Geodynamik (ZAMG), Vienna, A-1190, Austria \\ ${ }^{3}$ Deutsches Zentrum für Luft- und Raumfahrt e.V. (DLR), Oberpfaffenhofen, Germany \\ ${ }^{4}$ Swedish Meteorological and Hydrological Institute (SMHI), Norrkoping, SE-601 76, Sweden \\ ${ }^{5}$ Paris Lodron University of Salzburg (PLUS), Salzburg, A-5020, Austria \\ ${ }^{6}$ Flightkeys GmbH, Vienna, A-1060, Austria
}

Correspondence: Matthieu Plu (matthieu.plu@meteo.fr)

\begin{abstract}
.
High quality volcanic ash forecasts are crucial to minimize the economic impact of volcanic hazards on air traffic. Decisionmaking is usually based on numerical dispersion modeling with only one model realization. Given the inherent uncertainty of such approach, a multi-model multi-source term ensemble has been designed and evaluated for the Eyjafjallajökull eruption in

5 May 2010. Its use for air traffic management is discussed. Two multi-model ensembles were built: the first is based on the output of four dispersion models and their own implementation of ash ejection. All a priori model source terms were constrained by observational evidence of the volcanic ash cloud top as a function of time. The second ensemble is based on the same four dispersion models, which were run with three additional source terms: (i) a source term obtained with background modeling constrained with satellite data (a posteriori source term), (ii) its lower bound estimate, and (iii) its upper bound estimate. The a priori ensemble gives valuable information about the probability of ash dispersion during the early phase of the eruption, when observational evidence is limited. However, its evaluation with observational data reveals lower quality compared to the second ensemble. While the second ensemble ash column load and ash horizontal location compare well to satellite observations, 3D ash concentrations are negatively biased. This might be caused by the vertical distribution of ash, which is too much diluted in all model runs, probably due to defaults in the a posteriori source term and vertical transport and/or diffusion processes in all models. Relevant products for the air traffic management are horizontal maps of ash concentration quantiles (median, $75 \%$, $99 \%$ ) at a fine-resolved flight level grid. These maps can be used for route optimization in the areas where ash does not pose a direct and urgent threat to aviation. Cost-optimized consideration of such hazards will result in much less impact on flight cancellations, reroutings, and traffic flow congestions.
\end{abstract}




\section{Introduction}

Volcanic eruptions that spread out ash over large areas can have tremendous economic consequences, although they are relatively rare compared to other high-impact natural hazards (such as tropical cyclones, storms, etc). For instance, the eruption of Eyjafjallajökull in 2010 forced to cancel about 100000 flights and generated a 1.4 billion Euro loss to the airline operators (IATA, 2010). At that time, predefined procedures during such events were missing as well as the determination of hazardous ash concentration levels used to guide decisions to restrict the airspace (e.g., Bolić and Sivčev, 2011; Alexander, 2013).

To mitigate the consequences of such type of volcanic eruptions on aviation, improved forecasting of ash dispersion has been shown to be necessary (Bolić and Sivčev, 2011). At a world-wide level, this has been the duty of Volcanic Ash Advisory Centres (VAACs). In Europe, the London and Toulouse VAACs issue warnings and, since the Eyjafjallajökull eruption, also provide concentration charts at three vertical levels for three contamination levels: $\leq 2 \mathrm{mg} \mathrm{m}^{-3}$ (low contamination), $>2 \mathrm{mg} \mathrm{m}^{-3}$ and $<4 \mathrm{mg} \mathrm{m}^{-3}$ (medium contamination), and $\geq 4 \mathrm{mg} \mathrm{m}^{-3}$ (high contamination) (ICAO, 2016). These volcanic ash contamination charts (up to 18 hours ahead) indicate hazardous zones and hazard levels, which can be used by authorities for flight safety. This is important because high ash concentrations can lead to a failure of aircraft turbines during operation (Prata and Tupper, 2009; Guffanti et al., 2010). In parallel, other studies of the impact of ash on aircraft engines (Clarkson et al., 2016) have considered ash dosage (i.e., the accumulated mass of ash encountered by the aircraft along its track) as an important parameter. While medium ash concentration over long time can also be a safety issue, low ash dose can lead to longer term damage, which becomes an issue for engine maintenance as shorter intervals are needed in order to prevent performance loss (Clarkson et al., 2016).

Contaminated regions can be avoided by flight rerouting but this increases costs due to delays and additional fuel. Furthermore, it leads to increased soot and gas emissions and thus to an enhanced climate impact. As a consequence, a cost/loss rationale can be considered in regions where ash concentrations remain below the safety margins. If we learn from the experience of meteorological probabilistic weather forecasts (Richardson, 2000; Osinski and Bouttier, 2018; Fundel et al., 2019), probabilistic ash dispersion forecasts based on ensembles can have a large benefit compared to deterministic forecasts. For that reason, ensembles of dispersion models are also gaining increasing interest from flight planning providers and proof-of-concept studies are in progress (Steinheimer et al., 2016). In particular, Prata et al. (2019) showed how probabilistic ash forecasts could be used to make optimal decisions for air traffic management (ATM). Such applications require good estimates of ash concentrations in 4 dimensions (3D space and time) as well as their uncertainty. Cost-optimized consideration of such hazards can result in a significantly reduced impact on flight cancellations, rerouting, and traffic flow congestion during volcanic ash events (Rokitansky et al., 2019). Besides, there is a raising interest among the operational community (such as VAACs) to develop probabilistic forecast products in the future.

Volcanic ash charts are based on the outputs from numerical prediction models. As a consequence they are usually prone to large errors and uncertainties (Kristiansen et al., 2012; Dacre et al., 2016), which arise from the uncertainties in the ash source term, in the modelling of transport including meteorology, and the parameterisation of physical processes. Although these components have been improving thanks to active research (Beckett et al., 2020), it is highly probable that perfect models 
cannot be reached in a near future. The ash source term, i.e., the temporal evolution of volcanic ash mass emitted by the volcano at every vertical level and distributed over aerosol size groups, cannot be fully observed, and even after inversion of satellite observations some error and uncertainty remain (Kristiansen et al., 2012). Aerosol processes (sedimentation, wash and rain out, aggregation in the presence of liquid or solid water) and aerosol transport depend on the aerosols' representation in the model, and also on the meteorological conditions. The meteorological forecasts, for which error grows inevitably with time (Dacre et al., 2016) and which are essential input information for ash dispersion forecasts, also contribute significantly to uncertainties in ash forecasts.

60 Some studies emphasized the added value of ensembles to represent such uncertainty (Kristiansen et al., 2012) and recommended them to be used in the decision process (Prata et al., 2019). To address such needs, a multi-model approach has been developed during the European Natural Airborne Disaster Information and Coordination System for Aviation (EUNADICS$\mathrm{AV}$ ) project and assessed on several test cases. The outputs from several models were collected to build a mini-ensemble and probabilistic charts of ash concentrations. This ensemble has a $0.1^{\circ}$ horizontal resolution on a large Euro-Atlantic domain, and provides information on 13 vertical flight levels (FLs). The integration of these data into a flight-planning software and their relevance for ATM were shown during an exercise simulating a fictitious crisis situation (Hirtl et al., 2020).

The purpose of the present article is to provide more precise understanding of the performance and benefit of the multimodel multi-source-term ensemble approach developed during the EUNADICS-AV project, using measurements as reference for comparison. The performance of individual model runs performed with four models using four different source terms each, is also evaluated to better understand ensemble characteristics. The uncertainty of the meteorological conditions was not taken into account, i.e., meteorological analyses were concatenated with short term forecasts.

The study focuses on a particular period of the Eyjafjallajökull eruption from 13 to 20 May 2010, when ash spread across the North Sea and the Atlantic Ocean, and then over continental Europe. During this period, the amount of measurements was particularly high compared to other phases of the eruption. Dacre et al. (2016) pointed out a low predictability of the dispersion of ash during this period and they studied how the error grew with time. Their study emphasized the need for ensemble approaches in order to deal with uncertainty. For the same phase of the eruption, Kristiansen et al. (2012) compared two different models with different source terms. They showed overall a good agreement between models, and that the ensemble obtained as the mean ash concentration of the different models (a mean-ensemble) usually, but not generally, outperforms any of the models.

The outline of the present article is as follows: Section 2 gives a description of the models, the source terms, and the reference data. Section 3 compares the model outputs and evaluates them against reference observations. Section 4 presents how miniensembles are built and compares them to reference observations as well. Section 5 discusses how such an ensemble can be used in ATM for future eruptions. Conclusions are drawn in Section 6. 


\section{Models and observations}

\subsection{Ash dispersion models}

The four models used in the present study are shortly described below. These models are different by design (i.e., some are chemistry-transport or on-line coupled models, some are Lagrangian or Eulerian) and they have different aerosol schemes, which brings in a pragmatic compensation for some of the uncertainties, regardless the limited number of models. The source terms are described in a later Section (Sect. 2.2).

\subsubsection{FLEXPART (ZAMG)}

The FLEXPART Lagrangian particle dispersion model is a widely used multi-scale atmospheric transport modeling and analysis tool, operated both in the research and in operational domains since its start back in the 1990s. In particular, at ZAMG (Zentralanstalt für Meteorologie und Geodynamik, the Austrian Weather Service), FLEXPART (Stohl et al., 1998, 2005) is not only used to operationally assist the Austrian government in its nuclear emergency response activities but also to predict dispersion of volcanic ash and $\mathrm{SO}_{2}$ worldwide. It considers transport, mixing, gravitational settling, dry and wet deposition, radioactive decay, and simple linearized chemical reactions of gases. To model ash dispersion over Europe in this study, FLEXPART version 9 was used, and the convection parameterisation (Forster et al., 2007) was activated. Sub-grid scale terrain parameterisation was enabled which increases the mixing heights due to sub-grid scale orographic deviations deduced from the European Centre for Medium-Range Weather Forecasts (ECMWF) input field standard deviation of orography. The FLEXPART simulation was performed from 10 May to 20 May 2010, including a spin-up of 3 days.

Meteorological input data on an Atlantic-European domain from ECMWF-IFS (https://www.ecmwf.int, last access: June, 27th, 2020), merged from analyses and forecasts, had a 3-hourly temporal and $0.2^{\circ}$ horizontal resolution and were available at 91 vertical levels from the surface up to $0.01 \mathrm{hPa}$. ECMWF's vertical resolution varies with altitude, ranging from $15 \mathrm{~m}$ near the surface to $6700 \mathrm{~m}$ at $0.01 \mathrm{hPa}$.

For each source term (see Sect. 2.2), total volcanic ash mass was distributed over particles of 4, 6, 8, 10, 12, 14, 16, 18, and $25 \mu \mathrm{m}$ diameter. The difference between real and the model topography was accounted for by setting the lower vertical boundary of any emission profile to the actual volcanic vent height of $1666 \mathrm{~m}$ above sea level.

Mean ash concentration between selected flight levels was calculated from hourly-resolved model output, which was available on a $0.1^{\circ} \times 0.1^{\circ}$ latitude-longitude grid and at a regular $500 \mathrm{~m}$ vertical spacing.

\subsubsection{MATCH (SMHI)}

MATCH is a comprehensive Eulerian chemical-transport model for operation and research activities in a wide range of applications (Robertson et al., 1999; Andersson et al., 2007). This includes nuclear emergency, volcanic eruptions, and tropospheric chemistry modelling. The MATCH model has been applied for resolutions down to $500 \mathrm{~m}$ and up to the global scale. The model describes all transport phases like advection, diffusion, sedimentation, wet and dry deposition, and includes wet and dry 
chemistry and advanced codes for aerosol modelling of mineral dust and of secondary inorganic aerosols (sulphate, nitrate, and ammonia), and secondary organic aerosols (formed from organic gases) (Andersson et al., 2015). In this application aerosols are described with a single bin, given deposition and optical properties of secondary inorganic aerosols with a prescribed size distribution.

The meteorological forcing is taken from the ECMWF-IFS operational model in 3-hourly intervals on a $0.2^{\circ}$ grid for the European area from 10 May to 20 May 2010, implying a spin-up period of 3 days. The 91 available model levels up to about $80 \mathrm{~km}$ are lumped pair-wise to half the number of layers in order to reduce computational load. Output for the European domain is post-processed on the $0.1^{\circ}$ grid.

\subsubsection{MOCAGE (METEO-FRANCE)}

MOCAGE is a chemistry-transport model that is used for operational and research applications at Météo-France for air quality purposes. A light version of MOCAGE has also been developed and used for emergency dispersion modelling, including the ash forecasts operated by the Toulouse VAAC. The MOCAGE configuration used in the present study complies with the one described by Guth et al. (2016): It enables full tropospheric and stratospheric chemistry, primary aerosols (desert dust, sea salt, volcanic ash, black carbon, and organic carbon), and secondary aerosols (sulfate, nitrate, ammonium). The aerosol scheme represents various processes, as described by Guth et al. (2016): transport (advection and sub-grid transport), sedimentation, deposition (dry and wet), and interaction with gas-phase chemistry.

Volcanic ash mass is distributed into 6 bins, defined by the Krumbein $\phi$-scale. An aerosol diameter is defined as $d(\phi)=$ $10^{-3} 2^{-\phi} \mathrm{m}$ (Folch et al., 2016), and bins in MOCAGE are bounded by $\phi=10$ and $\phi=9$ for bin $1, \phi=9$ and $\phi=8$ for bin $2, \ldots, \phi=5$, and $\phi=4$ for bin 6 . The nested MOCAGE simulations run on a global domain at $1^{\circ}$ resolution, and on a large European domain at $0.2^{\circ}$ resolution. The lateral boundary conditions for the smaller domain are provided by the global domain, but only the output data from the high-resolution European domain are used in this study. The MOCAGE simulations start on 10 May 2010 at 00 UTC, including 3-days spin-up. Outputs are provided at an hourly step.

Input meteorological forcings have a 3-hourly resolution, they come from ARPEGE 6-hourly analyses, interspersed with 3-hours forecasts. MOCAGE has 47 vertical hybrid sigma-pressure levels from the surface up to $5 \mathrm{hPa}$. The vertical resolution varies with altitude, with a resolution of $40 \mathrm{~m}$ in the planetary boundary layer, about $400 \mathrm{~m}$ in the free troposphere, and about $700-800 \mathrm{~m}$ in the upper troposphere and lower stratosphere.

The MOCAGE ash concentrations in the European domain were post-processed on the $0.1^{\circ}$ grid, and interpolated to 13 vertical flight levels.

\subsubsection{WRF-Chem (ZAMG)}

The online-coupled chemical transport model WRF-Chem (Grell et al., 2005) is operationally used at ZAMG for air quality prediction over Europe with a special focus on Austria. This model simulates the emission, transport, mixing, and chemical reactions of trace gases and aerosols as well as meteorological conditions. WRF-Chem version 3.9 was run at a horizontal resolution of $12 \mathrm{~km}$ and at 47 vertical levels. Model domain extended from Greenland to Western Russia and from northern 
Africa towards about $75^{\circ} \mathrm{N}$. The following physical model options were used: the two-moment cloud microphysics scheme (Morrison et al., 2009), Rapid Radiative Transfer Method for Global (RRTMG) long-wave and short-wave radiation (Iacono et al., 2008), Grell 3D cumulus parameterisation (Grell and Freitas, 2014), NOAH land surface model (Chen and Dudhia, 2001), and the Mellor-Yamada-Nakanishi-Niino (MYNN) level 2.5 planetary boundary-layer (PBL) scheme (Nakanishi and Niino, 2004). WRF-Chem simulations were performed from 4 May to 20 May 2010.

In WRF-Chem, external meteorological data are only used as input and boundary conditions. Therefore, they need to extend over a slightly larger area than the modeling domain itself. For this study, these data were obtained from ECMWF every three hours with $0.25^{\circ}$ horizontal resolution and at 91 vertical levels.

For each volcanic source term, volcanic ash mass was distributed between 10 aerosol bins with diameter sizes ranging from about $3.9 \mu \mathrm{m}$ to $2 \mathrm{~mm}$ following the S2 classification scheme of Stuefer et al. (2013). Fine volcanic ash with particles smaller than $31.25 \mu \mathrm{m}$ accounted for $27.5 \%$ of total emitted ash.

Mean concentration of fine volcanic ash between selected flight levels was calculated after interpolating the hourly-resolved model output to the regular $0.1^{\circ} \times 0.1^{\circ}$ EUNADICS-AV grid.

\subsection{Source terms}

Every model uses two types of source terms: an a priori souce term and an a posteriori source term. A priori source terms are computed from simple schemes, e.g., using data such as plume height estimates as input information. The a posteriori source term was obtained after inversion of satellite total column estimates (Stohl et al., 2011).

For all models, the a priori source terms are, in a nutshell, derived from a plume model using plume height estimates from radar data (Arason et al., 2011). The plume models are respectively, PLUMERIA (Mastin, 2007) for FLEXPART, F-PLUME (Folch et al., 2016) for MOCAGE, and the Mastin et al. (2009) relationship, which relates plume height with emitted mass per time step, for MATCH and WRF-Chem. MATCH and WRF-Chem assume an umbrella-shaped plume with slightly different structures: while MATCH assigns $10 \%$ of the mass to below $25 \%$ of the plume height, $15 \%$ of the mass up to $50 \%$ of the plume height, and the remaining $75 \%$ of the mass to above $50 \%$ of the plume height, WRF-Chem assigns $25 \%$ of the mass from the vent height to the umbrella base (75\% of the plume top height) and $75 \%$ of the mass to the umbrella (Stuefer et al., 2013; Hirtl et al., 2019). Furthermore, radar plume heights used in both models were slightly different. The records of radar plume heights used in MATCH are those reported at the time of the Eyjafjallajökull eruption. Reports were provided for various durations from 3 to 21 hours (in steps of 3 hours). Some longer durations may just be a concatenate of repeated height levels in consecutive reports. For WRF-Chem, the $75 \%$ quantile of plume-top altitude statistics calculated for 3 hour time intervals and provided by Arason et al. (2011) is used.

The time-height evolution of the source term intensity differs significantly from one model to the other (Fig. 1). While all source terms emit most ash at high altitudes, FPLUME/MOCAGE emits very little ash at medium levels and only little ash near the ground. The transition from high to low emissions is smoother for the other models. Furthermore, topography of the volcanic vent, which is actually located at $1666 \mathrm{~m}$ above sea level (asl), is fully considered in FPLUME/MOCAGE and FLEXPART but neglected in MATCH and WRF-Chem. 
Contrary to the a priori source terms, the a posteriori source term is the same for all models. Described by Stohl et al. (2011), it is based on a Bayesian inverse modelling approach using FLEXPART in forward mode to establish the sensitivities between the emissions and the measurements. In this study, altitude and time resolved volcanic ash emissions were derived for the Eyjafjallajökull eruption in April and May 2010 using satellite observations. The data used was total column ash measurements of the Spinning Enhanced Visible and Infrared Imager (SEVIRI) aboard the geostationary Meteosat Second Generation (MSG) satellite and the Infrared Atmospheric Sounding Interferometer (IASI) aboard the polar orbiting Metop satellite, utilizing their high temporal coverage (SEVIRI) and enhanced sensitivity to ash (IASI). Furthermore, a priori estimated ash emissions based on observed plume heights and the eruption column model PLUMERIA (Mastin, 2007) were used. Validations with independent observations revealed improved model results when using the inversion-derived a posteriori ash emission source term rather than an a priori one (Stohl et al., 2011).

Based on an optimal estimation algorithm, the Stohl et al. (2011) source term provides an optimal value of the emission. There is, however, also uncertainty associated with the source term that is quantified as error variance after the inversion. In order to use this uncertainty, two additional source terms are built: a "lower bound" estimate of the ash emission and an "upper bound" estimate (Fig. 2). At each time and vertical level $(t, z)$ above the vent, Stohl et al. (2011) provide an optimal mass estimate and its error variance $\left(m, \sigma^{2}\right)$. Lower and upper bounds are derived from the assumption that these bounds equal the $15 \%$ and $85 \%$ quantiles, respectively, of a log-normal distribution with maximum likelihood $m$ and variance $\sigma^{2}$. The choice of a log-normal distribution is preferred to a normal one because it does not allow for negative values, despite the fact that the Stohl et al. (2011) inversion assumed a normal distribution of emission flux errors.

\subsection{VACOS reference ash observations}

The Volcanic Ash Cloud properties Obtained from SEVIRI algorithm (VACOS, Piontek et al., 2021b) derives volcanic ash coverage, ash optical thickness at $10.8 \mu \mathrm{m}$, mass column loads, volcanic ash plume height, and volcanic ash effective particle radius from data of the passive SEVIRI imager aboard the geostationary MSG satellite (Schmetz et al., 2002). SEVIRI is a twelve-channel instrument with a spatial resolution of $3 \mathrm{~km}$ at the sub-satellite point that diminishes towards the edges of the Earth disk. Its temporal resolution is $15 \mathrm{~min}$ in the operational mode over the Equator at $0^{\circ} \mathrm{E}$ for the entire disk. Thus, this instrument is well-suited for the continuous monitoring of volcanic ash clouds in the atmosphere.

The VACOS retrieval of volcanic ash used here is the follow-on version of the algorithm Volcanic Ash Detection Using Geostationary Satellites (VADUGS) developed after the Eyjafjallajökull eruption in 2010 (Kox et al., 2013; Graf et al., 2015; WMO, 2015, 2017; de Laat et al., 2020; Bugliaro et al., 2021). Like other spaceborne retrievals of volcanic ash (e.g. Prata, 1989a; Prata and Grant, 2001; Francis et al., 2012; Prata and Prata, 2012; Pavolonis et al., 2013; Pugnaghi et al., 2013; Piscini et al., 2014) it exploits the spectral signatures of volcanic ash in the atmosphere, in particular the reverse absorption effect between two window channels centred at 10.8 and $12.0 \mu \mathrm{m}$ (Prata, 1989a, b) and the information coming from all thermal SEVIRI channels. Thus, it is applicable during day and night. Moreover, VACOS uses auxiliary information like satellite viewing angle, surface temperature obtained from a numerical weather prediction (NWP) model, or clear sky brightness temperatures derived from the SEVIRI observations. VACOS consists of four artificial neural networks (ANNs) with three hidden layers and 100 
neurons each. While the development of the VADUGS and VACOS algorithms follows the ideas implemented in the related ice cloud retrievals COCS ("Cirrus Optical properties derived from CALIOP and SEVIRI algorithm during day and night", Kox et al., 2014) and CiPS ("Cirrus Properties from SEVIRI", Strandgren et al., 2017), the most important difference consists in the fact that the volcanic ash retrievals are trained using simulated SEVIRI thermal observations instead of collocated observations of ice clouds of the spaceborne lidar CALIPSO/CALIOP (Winker et al., 2009) as for COCS and CiPS. The VACOS input data set consists of brightness temperatures for the SEVIRI thermal channels corresponding to observations of volcanic ash under a multitude of meteorological conditions with a multitude of microphysical and macrophysical properties like plume bottom and top height as well as volcanic ash concentrations. Ash optical properties have been computed according to a set of representative refractive indices to encompass a large variety of possible volcanic eruptions (Piontek et al., 2021c). Furthermore, VACOS is trained to detect volcanic ash in cloud-free environments and also above liquid water clouds. Ice clouds are excluded a priori through the application of the dedicated ice cloud algorithm COCS mentioned above. VACOS has a fairly good volcanic ash detection probability for ash layers with column loads between 0.2 and $1 \mathrm{~g} \mathrm{~m}^{-2}$ (between 1 and $10 \mathrm{~g} \mathrm{~m}^{-2}$ ) of approximately $93 \%(99 \%)$ and also allows for the quantification of the ash load of the plume with a mean absolute percentage error of ca. $40 \%(26 \%)$. These values have been derived for a simulated test data set, using the retrieved ash optical depth at $10.8 \mu \mathrm{m}$, a typical mass extinction coefficient of $0.2 \mathrm{~m}^{2} \mathrm{~g}^{-1}$ and a threshold value of $0.2 \mathrm{~g} \mathrm{~m}^{-2}$ (Piontek et al., 2021a).

\subsection{Airborne measurements}

During the period of the study, airborne measurements were reported in the literature. A lidar onboard the Facility for Airborne Atmospheric Measurements (FAAM) BAe-146 research aircraft (Marenco et al., 2011) scanned ash layers to estimate ash load, ash layer height, and ash 3D concentrations above the United Kingdom and the North Sea. During the period of interest, measurements were performed on 14, 16, 17, and 18 May. Furthermore, DLR flights reported in-situ estimates of 3D ash concentrations above the North Sea, Germany, and the Netherlands (Schumann et al., 2011) on 13, 16, 17, and 18 May. In the present study, these data sets are used to assess the performance of individual models and both ensembles.

\subsection{Grids and post-processing}

All model results were provided with hourly resolution on a common $0.1^{\circ} \times 0.1^{\circ}$ horizontal grid from $30^{\circ} \mathrm{W}$ to $40^{\circ} \mathrm{E}$ in longitude and from $30^{\circ} \mathrm{N}$ to $75^{\circ} \mathrm{N}$ in latitude. The vertical discretization is defined by 13 flight levels from FL50 up to FL650 with 50 hecto feet steps. This common grid has been designed to facilitate the computation of scores on a uniform domain. The horizontal and vertical resolutions are significantly higher compared to past studies (Kristiansen et al., 2012; Dacre et al., 2016). 


\section{Differences between model outputs}

\subsection{Method and metrics}

Most of the model diagnostics presented in the article are based on the model data at $0.1^{\circ}$ resolution, except for the ash location scores compared to the VACOS observations, which are calculated in a smaller domain shown in Fig. 3 at $0.2^{\circ}$ resolution. Mean values are computed to pass the model $0.1^{\circ}$-resolution data to the $0.2^{\circ}$-resolution grid. For the $3 \mathrm{~km}$-resolved VACOS data, a $0.2^{\circ}$ grid cell is considered contaminated at instant $\mathrm{H}$, if a $50 \%$ fraction of VACOS pixels inside the $0.2^{\circ}$ grid box at $\mathrm{H}-15$ min, $\mathrm{H}$, and $\mathrm{H}+15 \mathrm{~min}$ are above $0.2 \mathrm{~g} \mathrm{~m}^{-2}$. This choice has been done after some tests of different thresholds and rules. It allows the detection of ash plumes (Fig. 3) while limiting noise and false alarms. Ash retrieval, however, is limited in the presence of clouds.

Figure 3 shows ash column load derived with the VACOS algorithm on several days. Ash load varies between $0.2 \mathrm{~g} \mathrm{~m}^{-2}$ and $2 \mathrm{~g} \mathrm{~m}^{-2}$, with highest values close to the volcano. Significant amounts of ash are found close to the British north-west coast and above Scotland on 14 and 16 May, which is in good agreement with Prata and Prata (2012), who also used SEVIRI data to derive Eyjafjallajökull volcanic ash concentrations. The distribution of ash load obtained by Prata and Prata (2012) peaks at $3 \mathrm{~g} \mathrm{~m}^{-2}$, while the VACOS ash load peaks between 1 and $2 \mathrm{~g} \mathrm{~m}^{-2}$. Comparisons between VACOS data and ash column mass loadings derived by Francis et al. (2012) on 17 May also reveal a rather good agreement, with around $1 \mathrm{~g} \mathrm{~m}^{-2}$ east of England. Over all dates considered, VACOS ash load is within the range of values found in the literature.

The Fraction Skill Score (FSS) is a meaningful metric to assess the performance of volcanic ash dispersion simulations by determining the scale over which a simulation has skill for the location of ash plumes along the horizontal dimensions (Harvey and Dacre, 2016). It is calculated as:

$F S S(r)=1-\frac{\sum_{j=1}^{N}\left[O_{j}(r)-M_{j}(r)\right]^{2}}{\sum_{j=1}^{N}\left[O_{j}^{2}(r)+M_{j}^{2}(r)\right]}$

with $N$ being the total number of grid points in the verification area, and $M_{j}(r)$ and $O_{j}(r)$ being the fractions of contaminated grid points within the circle of radius $r$ around point $j$, for the model and the observations, respectively. Before the computation of $F S S(r)$, a normalization step was applied, where the $G$ most contaminated grid points were determined for VACOS and model data. For VACOS, all grid points (within the verification area) with ash load higher than $0.2 \mathrm{~g} \mathrm{~m}^{-2}$ are assumed to be contaminated; $G$ is defined as number of these grid points. For each model output, the $G$ grid points with the highest ash concentration in the domain are kept for further analysis and used to calculate the FSS. This normalization step helps to keep only the most intense ash features in both models and observations and avoids the problem due to different magnitudes of ash load in the observation and the model. A model has skill at a given scale if the FSS is above 0.5; the higher the FFS, the better the model performance. 


\subsection{Ash location}

Generally speaking and not surprisingly, the FSS (Fig. 4) increases with the radius of detection $(50 \mathrm{~km}, 200 \mathrm{~km}, 500 \mathrm{~km})$. While the models FSSs-50km do not always exceed the 0.5 threshold, the FSSs-500km are clearly higher than 0.5, except after 19 May, when the eruption stopped and scores are less relevant. The FSSs based on the a posteriori source term (right panels) are generally higher than the ones based on the a priori source terms, particularly for the $50 \mathrm{~km}$ and $200 \mathrm{~km}$ radii. There is a large variability of scores between the models, although this variability is lower for the models with the same a posteriori source term. Snapshot ash load maps can help to analyse the FSS scores and the performances of the models and/or of the observation shortcomings, e.g., clouds hindering satellite observations.

On 16 May at 14 UTC, the highest values of ash in VACOS (Fig. 3) follow a plume that starts from Iceland and ends with a large patch of ash above Scotland. The simulated ash plumes have quite different shapes and magnitudes of ash load when using different a priori source terms (first row of Fig. 5). While all models capture the plume that crosses the Atlantic from Iceland to Scotland, the ash patch is not obvious or not well located in all models simulations. This explains the rather large differences in FSSs for $50 \mathrm{~km}$ and $200 \mathrm{~km}$ radii (left panels of Fig. 4; FSSs 50km/200km of a priori runs on 16 May at 14 UTC: MATCH=0.41/0.65, MOCAGE=0.46/0.69, FLEXPART=0.57/0.85, WRH-CHEM=0.40/0.60).

FSSs of the a posteriori source term runs at the same instant (right panels of Fig. 4) reveal that highest ash loads are better captured by the models (FSS 50km/200km of a posteriori runs on 16 May at 14 UTC: MATCH=0.43/0.71, MOCAGE=0.60/0.82, FLEXPART $=0.54 / 0.76$, WRH-CHEM=0.64/0.86). This is due to a better representation of the ash cloud above Scotland as seen in Fig. 5, third row.

Ash column load of the lower- and upper-bound simulations (second and fourth row of Fig. 5) show significant differences. At first sight, the differences between the different a posteriori source term bounds for the same model are in a similar range as the differences between two models with the same best estimate a posteriori source term. Comparison with ash load using the a priori source term (first row of Fig. 5) shows that the simulations with the a posteriori source terms do not reach the extreme values that can be reached with the simulation with the a priori source terms. The analysis and evaluation of model ash load on 14 May at 15 UTC and on 17 May at 16 UTC (suppl. material) support these findings.

As a conclusion, the comparison of FSSs and of ash column load maps helps to understand the relative performance of models and the origin of their differences. When using different (a priori) source terms, large differences in ash load magnitude can be observed. Using the same a posteriori source term generates simulations with similar magnitudes of ash load and similar location of ash in the models, but some differences in ash load and details in plume shapes are obvious. If models were forced by meteorological forecasts (instead of analyses), larger differences in plume location and ash load can be expected.

\subsection{Ash vertical distributions}

Cross-sections of ash concentrations on 16 May at 14 UTC (Fig. 6) reveal that ash tends to appear at all vertical levels from the ground up to the top of the plume. The simulations using different a priori source terms show quite different cross sections 
in shape and concentration load. The simulations with the same a posteriori source term show a rather similar shape, with the highest values following an eastward upward line. However, they differ significantly in intensity.

While all simulations show ash reaching the ground, the Marenco et al. (2011) airborne measurements, at the same time and in the same area, identified an ash layer only between 4 and $6 \mathrm{~km}$. This behaviour is also supported by cross sections shown in the supplementary material.

The presence of ash at all levels can be due to the source term or due to the representation of vertical processes in the models, and it is possible to provide arguments to help disentangling the two. For most of the source terms, except the MOCAGE a priori one, ash is injected at all layers. Before 16 May at 14 UTC (Fig. 1), the WRF-Chem a priori source term also concentrates ash in the upper levels. Since MOCAGE and WRF-Chem ash tends to extend largely along the vertical (Fig. 6), vertical parameterizations and processes including grid-scale vertical velocity, diffusion, aerosol sedimentation and/or vertical resolution should probably be improved. However, from this study alone, it is not possible to conclude whether the a posteriori source term is too much diluted along the vertical or not.

\section{Building ensembles and evaluating their quality}

Ensemble forecasting has a 30-years long history in meteorology (Buizza, 2019), from which some guidelines and pitfalls can be learned for an extension to volcanic dispersion forecasting. A first lesson learned is that all possible sources of uncertainty should be taken into account. The possible methods to take into account the uncertainty (perturbations or stochastic representation of features) can be diverse and have been an active field of research (Leutbecher et al., 2017). Another lesson learned is that the evaluation of ensembles is critical and is usually done based on long-period data sets for which homogeneous ensembles are run and compared against measurements. Usually, the evaluation metrics are used to further design the perturbation methods or bounds. Regarding rare events such a volcanic eruptions, for which observations are rare, evaluation of ensembles is clearly a more difficult task.

\subsection{Method}

Uniform grids facilitate the computation of the ensemble and the ingestion of model products into flight planning software (Hirtl et al., 2020). From the outputs of the four models on the same grid, mini-ensembles were computed. Ensembles in general provide probabilities of a model variable of interest, which is the ash mass in our present application. Based on the meteorological literature (Fundel et al., 2019), there are different ways to present and use ensemble outputs, that depend on the user requirements. In the EUNADICS-AV project, it has been argued that ash concentration maps at several flight levels are important as they can be used in the flight planning software. This allows for the computation of ash dose along flight tracks including its uncertainty by taking into account different levels of probability. Furthermore, flight rerouting should be enabled in in highly contaminated regions. So, the choice for this study has been to present the ensemble outputs as maps of ensemble quantiles, including the median, the $75 \%$-percentile (Q75), and the $99 \%$-percentile (Q99) of the concentration of 
ash at every grid point. These three concentration fields at all vertical levels can be used and treated by flight planning software, with different levels of risks.

Based on the different model simulations that were compared in the previous sections, two multi-model ensembles were built:

- a 4-members a priori ensemble, based on the 4 model simulations (FLEXPART, MATCH, MOCAGE, and WRF-Chem) with their own a priori source terms,

- a 12-members a posteriori ensemble, based on the 4 models (FLEXPART, MATCH, MOCAGE and WRF-Chem) using the a posteriori source term, its lower bound, and its upper bound ( 3 simulations per model).

Figure 7 shows ash column load of the a priori and a posteriori ensembles on 16 May at 14 UTC. For both ensembles, differences between the median and Q99 are obvious, which clearly reveals the benefit of the ensemble approach. The differences between the a priori and a posteriori ensemble are also quite large.

Evaluation of ensemble performance is done against VACOS ash location to assess the horizontal spread and against aircraft observations of lidar and in-situ measurements in order to evaluate simulated local ash load and ash concentrations along flight routes.

\subsection{Evaluation of ash location}

Like for the individual model outputs, ash location of ensemble outputs is evaluated using the FSS metric applied on a smaller domain shown in Fig. 3 at $0.2^{\circ}$ resolution. While the FSS can differ significantly from one model to another (Fig. 4), the FSS of ensemble quantiles (Fig. 8) are quite close to each other, except for some specific points in time. In that case, FSSs of the median are higher than the Q99 FSSs. In general, the a posteriori ensemble median performs better than the a priori ensemble median. This is also generally true for the higher quantiles, except for the Q99 on 17 and 18 May, when the Q99 quantiles of the a posteriori ensemble show lower performance than the a priori one. However, the differences are rather small. A possible explanation is that the Q99 a posteriori ensemble (suppl. material) does not catch the ash patch in the north of the Netherlands on 17 May (Fig. 3).

To summarize the capacity of ensemble quantiles to catch the regions of highest ash load, the different ensemble quantiles have similar performance, and the a posteriori ensemble performs generally better than the a priori ensemble.

\subsection{Evaluation of ash column load}

Evaluation of ash column load is done against the most precise airborne lidar measurements from Marenco et al. (2011). Fig. 9 summarizes how the ensemble performs at different points along three flight tracks: on 14 May around 15 UTC, on 16 May around 14 UTC, and on 17 May around 16 UTC. Not all the flight track is taken into account, but only some locations (referred to as $\boldsymbol{F}$ in Fig. 7), which correspond to points where the highest values of ash load were measured. For comparison, ensemble results are extracted from the few (4 to 9) grid points obtained along the flight track where those highest values were measured. VACOS data extracted at the same grid points are also superimposed. Although such evaluation does not provide a rigorous 
Table 1. Ash concentrations reported by DLR (Schumann et al., 2011) and FAAM (Marenco et al., 2011) flights, and estimates from the ensemble outputs. The flight level (in brackets) indicates the mid-level of the ensemble output layers closest to the actual flight track heights (from FL25 to FL625 by 50). The concentration measurements are expressed as a range of values ( $m_{\min }$ to $m_{\max }$ ) for DLR flights or for a mean value and uncertainty $\left(m_{\text {mean }} \pm \sigma\right)$ for FAAM flights.

\begin{tabular}{llllccc}
\hline $\begin{array}{l}\text { Flight } \\
\text { number }\end{array}$ & Time & Location & Height/FL & $\begin{array}{c}\text { Measurement } \\
\left(\mu \mathrm{g} \mathrm{m}^{-3}\right)\end{array}$ & $\begin{array}{c}\text { ENS-PRIOR (Q50/Q99) } \\
\left(\mu \mathrm{g} \mathrm{m}^{-3}\right)\end{array}$ & $\begin{array}{c}\text { ENS-POST (Q50/Q99) } \\
\left(\mu \mathrm{g} \mathrm{m}^{-3}\right)\end{array}$ \\
\hline DLR08 & $2010051314 \mathrm{UTC}$ & $53.4^{\circ} \mathrm{N} 1.5^{\circ} \mathrm{E}$ & $5.1 \mathrm{~km}(\mathrm{FL} 175)$ & 11 to 20 & $(7 / 17)$ & $(6 / 24)$ \\
FAAM-B528 & $2010051415 \mathrm{UTC}$ & $55.1^{\circ} \mathrm{N} 3^{\circ} \mathrm{W}$ & $6.5 \mathrm{~km}(\mathrm{FL} 225)$ & $700 \pm 200$ & $(92 / 511)$ & $(222 / 386)$ \\
DLR09 & $2010051614 \mathrm{UTC}$ & $54.8^{\circ} \mathrm{N} 0.2^{\circ} \mathrm{W}$ & $6.1 \mathrm{~km}(\mathrm{FL} 225)$ & 19 to 40 & $(6 / 1158)$ & $(3 / 192)$ \\
FAAM-B529 & $2010051614 \mathrm{UTC}$ & $55.1^{\circ} \mathrm{N} 3.7^{\circ} \mathrm{W}$ & $4.3 \mathrm{~km}(\mathrm{FL} 175)$ & $500 \pm 200$ & $(54 / 170)$ & $(31 / 84)$ \\
DLR10 & $2010051716 \mathrm{UTC}$ & $52.8^{\circ} \mathrm{N} 2.9^{\circ} \mathrm{E}$ & $5.2 \mathrm{~km}(\mathrm{FL} 175)$ & 105 to 283 & $(3 / 117)$ & $(3 / 50)$ \\
FAAM-B530 & $2010051716 \mathrm{UTC}$ & $54.1^{\circ} \mathrm{N} 1.5^{\circ} \mathrm{E}$ & $4.9 \mathrm{~km}(\mathrm{FL} 175)$ & $300 \pm 150$ & $(13 / 169)$ & $(18 / 94)$ \\
DLR11 & $2010051809 \mathrm{UTC}$ & $53.2^{\circ} \mathrm{N}, 9.1^{\circ} \mathrm{E}$ & $3.1 \mathrm{~km}(\mathrm{FL} 125)$ & 38 to 93 & $(15 / 170)$ & $(10 / 40)$ \\
DLR12 & $2010051810 \mathrm{UTC}$ & $48.8^{\circ} \mathrm{N} 10.0^{\circ} \mathrm{E}$ & $5.2 \mathrm{~km}(\mathrm{FL} 175)$ & 16 to 38 & $(13 / 336)$ & $(6 / 93))$ \\
\hline
\end{tabular}

probabilistic evaluation of the ensemble, it helps to characterize the ensemble dispersion and shows how the ensemble quantiles match the observations.

For the three episodes (Fig. 9), the airborne measurements fall in the range of the median, Q75, or Q99 ensemble values, which shows that the both ensembles capture the real ash load. The range from the median to Q99 is smaller for the a posteriori ensemble than for the a priori ensemble: the ensemble dispersion is smaller using the a posteriori source term, though keeping it large enough. The median of the a posteriori ensemble performs best, except that it is biased low on 17 May at 16 UTC, but the median of the a priori ensemble is always biased low. Of course, further calibration based on different test cases should be done to validate these results.

\subsection{Evaluation of 3D concentrations}

The evaluation of ash concentration is performed against DLR and FAAM aircraft measurements taken during their flight routes. In-situ ash measurements are rare, though some exist, particularly for the phase of the eruption studied in the present article. Table 1 compares in-situ airborne measurements with ensemble values (using the a priori and a posteriori source terms).

The maps of concentration values for different ensemble quantiles and the flight locations are shown in Fig. 10.

A general conclusion based on Table 1 is that the ash Q99 values based on the a priori source term are much higher than based on the a posteriori source term. This is consistent with the fact that the a priori member with maximum ash concentration yields generally higher values than the a posteriori member with maximum ash concentration (Figs. 5 and 9). On 13 May at 14 UTC (map not shown), the ash concentrations are low (around 10 to $20 \mu \mathrm{g} \mathrm{m}^{-3}$ ), in the measurements, but also in the ensemble, which are in a good agreement for both source terms. On the $14^{\text {th }}$, the aircraft flew through a rather ash-loaded 
area (between 500 and $900 \mu \mathrm{g} \mathrm{m}^{-3}$ ), which is also obviously polluted by ash according to the ensemble, as shown by the corresponding map (Fig .10), but with much lower concentration values (100 to $500 \mu \mathrm{g} \mathrm{m}^{-3}$ for both source terms).

However, where high ash concentrations are measured (above $200 \mu \mathrm{g} \mathrm{m}^{-3}$ ), the ensemble values generally tend to be lower. Even for the flight routes where modelled ash column loads are in reasonable agreement with the measurements (FAAM flights, Fig. 9), ash concentrations at the flight levels are significantly lower. An explanation, consistent with conclusions in previous parts of this article, is that ash is too much diluted along the vertical, due to the shape of the source term or to vertical dilution processes during ash transport. This is also true for the a posteriori source term which is constrained by ash load satellite estimates, but where the vertical distribution of ash is mainly constrained by the a priori.

\section{Discussion: use of ensembles in air traffic management}

Given the threat of ash for flight safety, and given the uncertainty of ash dispersion forecasts, the use of probabilistic products is important but not straightforward. Prata et al. (2019) introduced a risk-matrix approach that combines ash concentration and ash dosage (accumulated ash concentration along the flight route) with likelihood obtained from the ensemble uncertainty. Their ensemble was based on one model with different model parameters, source terms, and meteorology. It was evaluated on a synthetic hypothetical use case.

400 In this study on a real case, we found considerable differences in ash location and ash concentrations due to the model choice indicating that a multi-model ensemble increases information about uncertainty. Even though the a posteriori ensemble was, in general, in better agreement with the observations, an a priori ensemble is preferred for ATM as it is available in nearreal-time also during the early phase of an eruption. The a posteriori source term can only be computed if a sufficient number of measurements is available. Due to the limited number of ground-based measurements, the missing temporal coverage of measurements on polar-orbiting satellites, and only a few instruments on geostationary satellites, it usually takes a couple of days to gather sufficient high-quality ash measurements to compute the a posteriori source term. Thus, a better quality of past ash dispersion and therefore better initial conditions for upcoming ash forecasts, can only be obtained after several hours or even a few days. An a priori ensemble includes different realizations of the source term, the most important component of ash dispersion uncertainty. The wide range of these a priori ash dispersion forecasts, however, might result in too conservative ATM, which can only be eased when a refined a posteriori source term is available. An intermediate approach could be to update the a priori source term continuously by constraining the assumptions of the source term evolution with updated measurements.

The evaluation of both ensembles revealed that ash location and load is in good agreement with the observations. However, the vertical structure of ash clouds is not correctly represented by the models and ash concentrations at individual flight levels are biased low. Therefore, care must be taken concerning flight rerouting. Flying between distinct layers of ash would only

415 be possible knowing the precise vertical structure of ash clouds, which is clearly not the case. However, model performance allows flying above clouds and also around highly contaminated regions.

Ash concentrations smaller $2 \mathrm{mg} \mathrm{m}^{-3}$ are considered safe. Ash concentrations higher than $80 \mathrm{mg} \mathrm{m}^{-3}$ are definitely considered unsafe (Clarkson et al., 2016). Following a conservative approach, we therefore recommend avoiding regions within the 
$2 \mathrm{mg} \mathrm{m}^{-3}$ contour line of the Q99 of the apriori ensemble. Looking at Fig. 10, such no-fly areas would include a small band south-east of Iceland on 16 May and a larger band which spreads from the east of Iceland along $65^{\circ}$ latitude towards the North Sea on 17 May. Indeed, these two days were most severely affected by flight cancellations during the considered time period of this study. On the 16/17 May, 20\%/31\% of all flights were canceled in Ireland and 19\%/26\% in the U.K (EUROCONTROL, 2010). Knowing that the vertical distribution of ash is not correctly represented in the models, vertical cross sections can nevertheless be used to estimate the upper limit of the ash cloud. The cross sections shown in Fig. 11 reveal high ash concentration on 17 May close to the meridian up to FL200. Considering the entire 3D field of ash concentration and using an appropriate ATM software (Rokitansky et al., 2019; Hirtl et al., 2020) would help to avoid these regions.

Flight cancellations can therefore be avoided by flying through lower contaminated regions as demonstrated during the EUNADICS-AV exercise (Hirtl et al., 2020). To estimate the long-term damage due to high ash dose, we recommend using the median of the ensemble as this gives the best estimate of ash distribution. Maintenance intervals of individual aircrafts can then be obtained with ATM software accumulating ash dose along relevant flight routes. In a later perspective, the quantiles can be used to optimize the cost/loss function, in a similar approach as the one developed by other end-users of meteorological ensemble forecasting (Richardson, 2000).

This approach would lead to a better management during future volcanic eruption crises. Probabilistic ash concentration forecasts, combined with safe "no-fly" areas could become the future operational ash products, allowing cost-optimized consideration of such hazards. This will result in much less impact on flight cancellations, reroutings, and traffic flow congestions during volcanic ash events.

\section{Summary and conclusions}

This article has presented an inter-comparison of volcanic ash forecasts using different models and different source terms for the Eyjafjallajökull eruption in May 2010. Furthermore, a methodology to build and use an ensemble for ATM was discussed. Most important findings include:

- large differences in ash location and ash load were found when models were run with their individual a priori source terms, which confirms that ash dispersion forecasts are highly sensitive to the volcanic ash source term;

- perturbed a posteriori source terms can be shared and used as input for any model yielding a multi-model ensemble; this a posteriori ensemble performs satisfactorily for ash location in two dimensions and for ash column load.

- the main shortcoming of all simulations is the vertical representation of ash concentration, which is evenly distributed over a wide vertical range without distinct layers of ash; therefore, the vertical distribution of ash needs to be improved - in relation to the source term, even after inversion, but also as a consequence of vertical aerosol processes in models (sedimentation, diffusion, aggregation). Even with a vertically-layered source term, there is high vertical diffusion of concentrations some hours after the emission; 
- quantiles of concentrations are a relevant products for ATM; they can be used for route optimization in the areas where ash does not pose a direct and urgent threat to aviation. Probabilistic ash concentration forecasts combined with safe "no-fly" areas can become a future operational product for ATM;

- the a priori ensemble is available in near-real-time also in the early phase of an eruption but the wide range of ash dispersion might be too conservative for ATM. This behaviour might be case-dependent, although experience shows that a priori source terms rather overestimate ash emissions. Therefore, flight rerouting can be based first on an a priori ensemble, and only at an later stage, when the a posterori ensemble is available, less conservative approaches can be taken for flying through low-concentration ash clouds.

In this study, only source term and model process uncertainty have been taken into account. In real conditions, the meteorological forecast error cannot be neglected and would also increase the spread in plume location and ash column loads.

A rigorous evaluation of any ensemble should be done for a large number of cases, which is difficult for rare events such as volcanic eruptions. Besides, only few measurements are available, hindering a comprehensive ensemble evaluation. The use of observations by assimilation along the vertical (such as lidar data) could also improve the model and ensemble representation of ash, even though such measurements remain rare and are available only where the ash plume is thin enough to be penetrated by the lidar.

The proposed methodology cannot only applied for ash dispersion during volcanic eruptions but also for other air pollutants, such as $\mathrm{SO}_{2}$, desert dust, or forest fires. Every airspace closure or even re-routing of planes can immediately increase the costs for airliners which will lead to a certain risk acceptance to fly nevertheless at least through regions which are below the safety-critical pollutant concentration threshold. For future natural disasters, cost and disruption of air traffic can be eliminated to a great extent by including the results of dispersion models into flight planning software to apply cost-based trajectory optimizations.

Data availability. The ensemble data is available in NetCDF, CF-compliant format, upon request to the corresponding author. The ash concentration, as described in the article, cover the percentiles Q50, Q75, Q99, on $13 \mathrm{FL}$, on a $0.1^{\circ}$ resolution grid. Instants of validity are from 13 to 20 May 2010, at an hourly step. Two ensembles are available: one using the a priori source terms, one using the a posteriori source terms. contributed to article plan and text. With MH and RB, she designed and ran WRF-Chem. GB and LEA designed and ran MOCAGE. GB developed some model scores. AC and LR designed and ran MATCH. DAA, CM, and MDM designed and ran FLEXPART. LB and DP provided VACOS data and information for the study. CHR, KE, FZ, and RZ contributed to the ATM-related text. 
https://doi.org/10.5194/nhess-2021-96

Preprint. Discussion started: 9 April 2021

(c) Author(s) 2021. CC BY 4.0 License.

(c) (i)

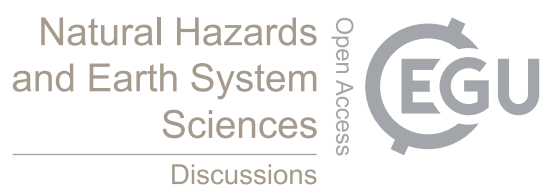

Competing interests. The authors do not have competing interests.

480 Acknowledgements. This work has been conducted within the framework of the EUNADICS-AV project, which received funding from the European Union's Horizon 2020 research programme for Societal challenges - smart, green and integrated transport under grant agreement no. 723986. 
https://doi.org/10.5194/nhess-2021-96

Preprint. Discussion started: 9 April 2021

(c) Author(s) 2021. CC BY 4.0 License.

\section{References}

Alexander, D.: Volcanic ash in the atmosphere and risks for civil aviation: A study in European crisis management, Int. J. Disaster Risk Sci., 4, 9-19, https://doi.org/10.1007/s13753-013-0003-0, 2013.

Andersson, C., Langner, J., and Bergström, R.: Interannual variation and trends in air pollution over Europe due to climate variability during 1958 - 2001 simulated with a regional CTM coupled to the ERA40 reanalysis, Tellus, 59B, 77-98, 2007.

Andersson, C., Bergström, R., Bennet, C., Robertson, L., Thomas, M., Korhonen, H., Lehtinen, K., and Kokkola, H.: MATCH-SALSA Multi-scale Atmospheric Transport and Chemistry model coupled to the SALSA aerosol microphysics model - Part 1: Model description and evaluation, Geosci. Model Dev., 8, 171-189, 2015.

Arason, P., Petersen, G. N., and Bjornsson, H.: Observations of the altitude of the volcanic plume during the eruption of Eyjafjallajökull, April-May 2010, Earth System Science Data, 3, 9-17, https://doi.org/10.5194/essd-3-9-2011, https://www.earth-syst-sci-data.net/3/9/ $2011 /, 2011$.

Beckett, F. M., Witham, C. S., Leadbetter, S. J., Crocker, R., Webster, H. N., Hort, M. C., Jones, A. R., Devenish, B. J., and Thomson, D. J.: Atmospheric Dispersion Modelling at the London VAAC: A Review of Developments since the 2010 Eyjafjallajökull Volcano Ash Cloud, Atmosphere, 11, https://doi.org/10.3390/atmos11040352, https://doi.org/10.3390/atmos11040352, 2020.

Bolić, T. and Sivčev, Z.: Eruption of Eyjafjallajökull in Iceland: Experience of European Air Traffic Management, Transport. Res. Rec., 2214, 136-143, https://doi.org/10.3141/2214-17, 2011.

Bugliaro, L., Piontek, D., Graf, K., Schmidl, M., Kox, S., Mayer, B., Müller, R., and Gasteiger, J.: Volcanic ash remote sensing with MSG/SEVIRI using an artificial neural network, tbc, 2021.

Buizza, R.: Introduction to the special issue on "25 years of ensemble forecasting", Q. J. R. Meteorol. Soc., 145, 1-11, https://doi.org/10.1002/qj.3370, 2019.

Chen, F. and Dudhia, J.: Coupling an advanced land surface-hydrology model with the Penn state-NCAR MM5 modeling system. Part I: Model implementation and sensitivity, Mon. Wea. Rev., 129, 569-585, https://doi.org/10.1175/15200493(2001)129<0569:CAALSH>2.0.CO;2, 2001.

Clarkson, R. J., Majewicz, E. J. E., and Mack, P.: A re-evaluation of the 2010 quantitative understanding of the effects volcanic ash has on gas turbine engines, Proc IMechE Part G: J Aerospace Engineering, 230, 2274-2291, https://doi.org/10.1177/0954410015623372, 2016.

Dacre, H. F., Harvey, N. J., Webley, P. W., and Morton, D.: How accurate are volcanic ash simulations of the 2010 Eyjafjallajökull eruption?, J. Geophys. Res. Atmos., 121, 3534-3547, https://doi.org/10.1002/2015JD024265, 2016.

510 de Laat, A., Vazquez-Navarro, M., Theys, N., and Stammes, P.: Analysis of properties of the 19 February 2018 volcanic eruption of Mount Sinabung in S5P/TROPOMI and Himawari-8 satellite data, Natural Hazards and Earth System Sciences, 20, 1203-1217, https://doi.org/10.5194/nhess-20-1203-2020, https://nhess.copernicus.org/articles/20/1203/2020/, 2020.

EUROCONTROL: Ash-cloud of April and May 2010: Impact on Air Traffic, Statfor/doc394 v1.0 28/6/10, EUROCONTROL/CND/STATFOR, $\quad$ https://www.eurocontrol.int/publication/ash-cloud-april-and-may-2010-impact-air-traffic(lastaccess:

515 12February2021), 2010.

Folch, A., Costa, A., and Macedonio, G.: FPLUME-1.0: An integral volcanic plume model accounting for ash aggregation, Geosci. Model Dev., 9, 431-450, https://doi.org/10.5194/gmd-9-431-2016, 2016.

Forster, C., Stohl, A., and Seibert, P.: Parameterization of convective transport in a Lagrangian particle dispersion model and its evaluation, J. Appl. Meteor. Climatol., 46, 403-422, https://doi.org/10.1175/JAM2470.1, 2007. 
https://doi.org/10.5194/nhess-2021-96

Preprint. Discussion started: 9 April 2021

(c) Author(s) 2021. CC BY 4.0 License.

Francis, P. N., Cooke, M. C., and Saunders, R. W.: Retrieval of physical properties of volcanic ash using Meteosat: A case study from the 2010 Eyjafjallajökull eruption, Journal of Geophysical Research: Atmospheres, 117, D00U09, https://doi.org/10.1029/2011JD016788, 2012.

Fundel, V. J., Fleischhut, N., Herzog, S. M., Göber, M., and Hagedorn, R.: Promoting the use of probabilistic weather forecasts through a dialogue between scientists, developers and end-users, Quarterly Journal of the Royal Meteorological Society, 145, 210-231, https://doi.org/https://doi.org/10.1002/qj.3482, 2019.

Graf, K., Kox, S., Schmidl, M., and Gasteiger, J.: VADUGS algorithm: Volcanic Ash Detection using Geostationary Satellites, 2015.

Grell, G. A. and Freitas, S. R.: A scale and aerosol aware stochastic convective parameterization for weather and air quality modeling, Atmos. Chem. Phys., 14, 5233-5250, https://doi.org/10.5194/acp-14-5233-2014, 2014.

Grell, G. A., Peckham, S. E., Schmitz, R., McKeen, S. A., Frost, G., Skamarock, W. C., and Eder, B.: Fully coupled "online" chemistry within the WRF model, Atmos. Environ., 39, 6957-6975, https://doi.org/10.1016/j.atmosenv.2005.04.027, 2005.

Guffanti, M., Casadevall, T. J., and Budding, K.: Encounters of aircraft with volcanic ash clouds; A compilation of known incidents, 1953-2009, U.s. geological survey data series 545, U.S. Department of the Interior and U.S. Geological Survey, http://pubs.usgs.gov/ ds/545, plus 4 appendixes including the compilation database, 2010.

Guth, J., Josse, B., Marécal, V., Joly, M., and Hamer, P.: First implementation of secondary inorganic aerosols in the MOCAGE version R2.15.0 chemistry transport model, Geosci. Model Dev., 9, 137-160, https://doi.org/10.5194/gmd-9-137-2016, 2016.

Harvey, N. J. and Dacre, H. F.: Spatial evaluation of volcanic ash forecasts using satellite observations, Atmos. Chem. Phys., 16, 861-872, https://doi.org/10.5194/acp-16-861-2016, 2016.

Hirtl, M., Stuefer, M., Arnold, D., Grell, G., Maurer, C., Natali, S., Scherllin-Pirscher, B., and Webley, P.: The effects of simulating volcanic aerosol radiative feedbacks with WRF-Chem during the Eyjafjallajökull eruption, April and May 2010, Atmos. Environ., 198, 194-206, https://doi.org/10.1016/j.atmosenv.2018.10.058, 2019.

Hirtl, M., Arnold, D., Baro, R., Brenot, H., Coltelli, M., Eschbacher, K., Hard-Stremayer, H., Lipok, F., Maurer, C., Meinhard, D., Mona, L., Mulder, M. D., Papagiannopoulos, N., Pernsteiner, M., Plu, M., Robertson, L., Rokitansky, C.-H., Scherllin-Pirscher, B., Sievers, K., Sofiev, M., Som de Cerff, W., Steinheimer, M., Stuefer, M., Theys, N., Uppstu, A., Wagenaar, S., Winkler, R., Wotawa, G., Zobl, F., and Zopp, R.: A volcanic-hazard demonstration exercise to assess and mitigate the impacts of volcanic ash clouds on civil and military aviation, Natural Hazards and Earth System Sciences, 20, 1719-1739, https://doi.org/10.5194/nhess-20-1719-2020, 2020.

Iacono, M. J., Delamere, J. S., Mlawer, E. J., Shephard, M. W., Clough, S. A., and Collins, W. D.: Radiative forcing by long-lived greenhouse gases: Calculations with the AER radiative transfer models, J. Geophys. Res., 113, D13103, https://doi.org/10.1029/2008JD009944, 2008.

IATA: IATA annual report 2010, Tech. rep., International Air Transport Association, https://www.iata.org/contentassets/ c81222d96c9a4e0bb4ff6ced0126f0bb/iataannualreport2010.pdf, 2010.

550 ICAO: Volcanic Ash Contingency Plan - European and North Atlantic Regions, EUR Doc 019, NAT Doc 006, Part II - EUR/NAT VACP, International Civil Aviation Organisation, https://www.icao.int/EURNAT/EURandNATDocuments/EUR+NATVACP.pdf, 2016.

Kox, S., Schmidl, M., Graf, K., Mannstein, H., Buras, R., and Gasteiger, J.: A new approach on the detection of volcanic ash clouds, in: Proceedings of The 2013 EUMETSAT Meteorological Satellite Conference, 2013.

Kox, S., Bugliaro, L., and Ostler, A.: Retrieval of cirrus cloud optical thickness and top altitude from geostationary remote sensing, Atmos. Meas. Tech., 7, 3233-3246, https://doi.org/10.5194/amt-7-3233-2014, 2014.

Kristiansen, N. I., Stohl, A., Prata, A. J., Bukowiecki, N., Dacre, H., Eckhardt, S., Henne, S., Hort, M. C., Johnson, B. T., Marenco, F., Neininger, B., Reitebuch, O., Seibert, P., Thomson, D. J., Webster, H. N., and Weinzierl, B.: Performance assessment of a volcanic 
ash transport model mini-ensemble used for inverse modeling of the 2010 Eyjafjallajökull eruption, J. Geophys. Res. Atmos., 117, https://doi.org/10.1029/2011JD016844, 2012.

Leutbecher, M., Lock, S.-J., Ollinaho, P., Lang, S. T. K., Balsamo, G., Bechtold, P., Bonavita, M., Christensen, H. M., Diamantakis, M., Dutra, E., English, S., Fisher, M., Forbes, R. M., Goddard, J., Haiden, T., Hogan, R. J., Juricke, S., Lawrence, H., MacLeod, D., Magnusson, L., Malardel, S., Massart, S., Sandu, I., Smolarkiewicz, P. K., Subramanian, A., Vitart, F., Wedi, N., and Weisheimer, A.: Stochastic representations of model uncertainties at ECMWF: state of the art and future vision, Quarterly Journal of the Royal Meteorological Society, 143, 2315-2339, https://doi.org/https://doi.org/10.1002/qj.3094, 2017.

Marenco, F., Johnson, B., Turnbull, K., Newman, S., Haywood, J., Webster, H., and Ricketts, H.: Airborne lidar observations of the 2010 Eyjafjallajökull volcanic ash plume, Journal of Geophysical Research: Atmospheres, 116, D00U05, https://doi.org/10.1029/2011JD016396, 2011.

Mastin, L., Guffanti, M., Servranckx, R., Webley, P., Barsotti, S., Dean, K., Durant, A., Ewert, J., Neri, A., Rose, W., et al.: A multidisciplinary effort to assign realistic source parameters to models of volcanic ash-cloud transport and dispersion during eruptions, Journal of Volcanology and Geothermal Research, 186, 10-21, 2009.

Mastin, L. G.: A user-friendly one-dimensional model for wet volcanic plumes, Geochem. Geophys. Geosyst., 8, Q03014, https://doi.org/10.1029/2006GC001455, 2007.

Morrison, H., Thompson, G., and Tatarskii, V.: Impact of cloud microphysics on the development of trailing stratiform precipitation in a simulated squall line: Comparison of one- and two-moment schemes, Mon. Wea. Rev., 137, 991-1007, https://doi.org/10.1175/2008MWR2556.1, 2009.

Nakanishi, M. and Niino, H.: An improved Mellor-Yamada level-3 model with condensation physics: Its design and verification, Bound.Layer Meteor., 112, 1-31, https://doi.org/10.1023/B:BOUN.0000020164.04146.98, 2004.

Osinski, R. and Bouttier, F.: Short-range probabilistic forecasting of convective risks for aviation based on a lagged-average-forecast ensemble approach, Meteorol. App., 25, 105-118, https://doi.org/https://doi.org/10.1002/met.1674, 2018.

Pavolonis, M. J., Heidinger, A. K., and Sieglaff, J.: Automated retrievals of volcanic ash and dust cloud properties from upwelling infrared measurements, Journal of Geophysical Research: Atmospheres, 118, 1436-1458, https://doi.org/https://doi.org/10.1002/jgrd.50173, https: //agupubs.onlinelibrary.wiley.com/doi/abs/10.1002/jgrd.50173, 2013.

Piontek, D., Bugliaro, L., Kar, J., Schumann, U., Marenco, F., Plu, M., and Voigt, C.: A new Volcanic Ash Retrieval for MSG-SEVIRI based on Artificial Neural Networks: 2. Validation, tbd, 2021a.

Piontek, D., Bugliaro, L., Schmidl, M., Zhou, D., and Voigt, C.: A new Volcanic Ash Retrieval for MSG-SEVIRI based on Artificial Neural Networks: 1. Development, tbd, 2021 b.

Piontek, D., Hornby, A., Voigt, C., Bugliaro, L., and Gasteiger, J.: Determination of complex refractive indices and optical properties of volcanic ashes in the thermal infrared based on generic petrological compositions, J. Volcanol. Geotherm. Res., 411, 107 174, https://doi.org/10.1016/j.jvolgeores.2021.107174, http://www.sciencedirect.com/science/article/pii/S0377027321000032, 2021c.

Piscini, A., Picchiani, M., Chini, M., Corradini, S., Merucci, L., Del Frate, F., and Stramondo, S.: A neural network approach for the simultaneous retrieval of volcanic ash parameters and $\mathrm{SO}_{2}$ using MODIS data, Atmospheric Measurement Techniques, 7, 4023-4047, https://doi.org/10.5194/amt-7-4023-2014, https://amt.copernicus.org/articles/7/4023/2014/, 2014.

Prata, A. J.: Observations of volcanic ash clouds in the 10-12-micron window using AVHRR/2 Data, Int. J. Remote Sens., 10, 751-761, 1989a.

Prata, A. J.: Radiative transfer calculations for volcanic ash clouds, Geophys. Res. Lett., 16, 1293-1296, 1989 b. 
Prata, A. J. and Grant, I. F.: Retrieval of microphysical and morphological properties of volcanic ash plumes from satellite data: Application to Mt Ruapehu, New Zealand, Quarterly Journal of the Royal Meteorological Society, 127, 2153-2179, https://doi.org/https://doi.org/10.1002/qj.49712757615, https://rmets.onlinelibrary.wiley.com/doi/abs/10.1002/qj.49712757615, 2001.

Prata, A. J. and Prata, A. T.: Eyjafjallajökull volcanic ash concentrations determined using Spin Enhanced Visible and Infrared Imager measurements, J. Geophys. Res., 117, D00U23, https://doi.org/10.1029/2011JD016800, 2012.

Prata, A. J. and Tupper, A.: Aviation hazards from volcanoes: the state of the science, Nat. Hazards, 117, D00U23, https://doi.org/10.1007/s11069-009-9415-y, 2009.

Prata, A. T., Dacre, H. F., Irvine, E. A., Mathieu, E., Shine, K. P., and Clarkson, R. J.: Calculating and communicating ensemble-based volcanic ash dosage and concentration risk for aviation, Meteorological Applications, 26, 253-266, https://doi.org/10.1002/met.1759, 2019.

Pugnaghi, S., Guerrieri, L., Corradini, S., Merucci, L., and Arvani, B.: A new simplified approach for simultaneous retrieval of $\mathrm{SO}_{2}$ and ash content of tropospheric volcanic clouds: an application to the Mt Etna volcano, Atmospheric Measurement Techniques, 6, 1315-1327, https://doi.org/10.5194/amt-6-1315-2013, https://amt.copernicus.org/articles/6/1315/2013/, 2013.

Richardson, D. S.: Skill and economic value of the ECMWF Ensemble Prediction System, Q. J. Roy. Meteorol. Soc., 126, 649-668, 2000.

Robertson, L., Langner, J., and Engardt, M.: An Eulerian Limited-Area Atmospheric Transport Model, J. Appl. Meteor., 38 (2), 190-210, 1999.

Rokitansky, C.-H., Eschbacher, K., Zobl, F., and Zopp, R.: Benefit Assessment Report on new integrated prototype products and impact on European airspace, 2019.

Schmetz, J., Pili, P., Tjemkes, S., Just, D., Kerkmann, J., Rota, S., and Ratier, A.: AN INTRODUCTION TO METEOSAT SECOND GENERATION (MSG), Bulletin of the American Meteorological Society, 83, 977-992, https://doi.org/10.1175/15200477(2002)083<0977:AITMSG>2.3.CO;2, https://journals.ametsoc.org/view/journals/bams/83/7/1520-0477_2002_083_0977_aitmsg_ 2_3_co_2.xml, 2002.

Schumann, U., Weinzierl, B., Reitebuch, O., Schlager, H., Minikin, A., Forster, C., Baumann, R., Sailer, T., Graf, K., Mannstein, H., Voigt, C., Rahm, S., Simmet, R., Scheibe, M., Lichtenstern, M., Stock, P., Rüba, H., Schäuble, D., Tafferner, A., Rautenhaus, M., Gerz, T., Ziereis, H., Krautstrunk, M., Mallaun, C., Gayet, J.-F., Lieke, K., Kandler, K., Ebert, M., Weinbruch, S., Stohl, A., Gasteiger, J., Groß, S., Freudenthaler, V., Wiegner, M., Ansmann, A., Tesche, M., Olafsson, H., and Sturm, K.: Airborne observations of the Eyjafjalla volcano ash cloud over Europe during air space closure in April and May 2010, Atmos. Chem. Phys., 11, 2245-2279, https://doi.org/10.5194/acp11-2245-2011, 2011.

Steinheimer, M., Gonzaga-Lopez, C., Kern, C., Kerschbaum, M., Strauss, L., Eschbacher, K., Mayr, M., and Rokitansky, C.-H.: Air traffic management and weather: the potential of an integrated approach, in: INAIR 2016, edited by Hromádka, M., pp. 120-126, EDIS Publishing Centre of University of Žilina, https://www.inair.uniza.sk/obsah/zbornik/INAIR_2016_ISSN.pdf, 2016.

Stohl, A., Hittenberger, M., and Wotawa, G.: Validation of the Lagrangian particle dispersion model FLEXPART against large scale tracer experiment data, Atmos. Environ., 32, 4245-4264, https://doi.org/10.1016/S1352-2310(98)00184-8, 1998.

Stohl, A., Forster, C., Frank, A., Seibert, P., and Wotawa, G.: Technical note: The Lagrangian particle dispersion model FLEXPART version 6.2, Atmos. Chem. Phys., 5, 2461-2474, https://doi.org/10.5194/acp-5-2461-2005, 2005.

Stohl, A., Prata, A. J., Eckhardt, S., Clarisse, L., Durant, A., Henne, S., Kristiansen, N. I., Minikin, A., Schumann, U., Seibert, P., Stebel, K., Thomas, H. E., Thorsteinsson, T., Tørseth, K., and Weinzierl, B.: Determination of time- and height-resolved volcanic ash emis- 
https://doi.org/10.5194/nhess-2021-96

Preprint. Discussion started: 9 April 2021

(c) Author(s) 2021. CC BY 4.0 License.

(c) (i)

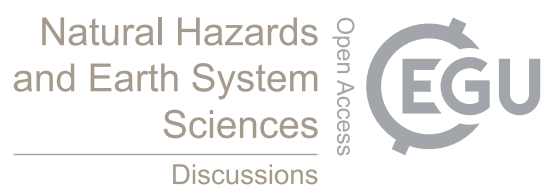

sions and their use for quantitative ash dispersion modeling: the 2010 Eyjafjallajökull eruption, Atmos. Chem. Phys., 11, 4333-4351, https://doi.org/10.5194/acp-11-4333-2011, 2011.

635 Strandgren, J., Bugliaro, L., Sehnke, F., and Schröder, L.: Cirrus cloud retrieval with MSG/SEVIRI using artificial neural networks, Atmospheric Measurement Techniques, 10, 3547-3573, https://doi.org/10.5194/amt-10-3547-2017, https://amt.copernicus.org/articles/10/ 3547/2017/, 2017.

Stuefer, M., Freitas, S. R., Grell, G., Webley, P., Peckham, S., McKeen, S. A., and Egan, S. D.: Inclusion of ash and SO2 emissions from volcanic eruptions in WRF-Chem: development and some applications, Geosci. Model Dev., 6, 457-468, https://doi.org/10.5194/gmd-6457-2013, 2013.

Winker, D. M., Vaughan, M. A., Omar, A., Hu, Y., Powell, K. A., Liu, Z., Hunt, W. H., and Young, S. A.: Overview of the CALIPSO Mission and CALIOP Data Processing Algorithms, Journal of Atmospheric and Oceanic Technology, 26, 2310-2323, https://doi.org/10.1175/2009JTECHA1281.1, https://journals.ametsoc.org/view/journals/atot/26/11/2009jtecha1281_1.xml, 2009.

WMO: Final Report of the Meeting on the Intercomparison of Satellite-based Volcanic Ash Retrieval Algorithms, Tech. rep., World Meteorological Organisation, 29 June-2 July 2015, 2015.

WMO: SCOPE Nowcasting, Volcanic Ash Algorithm Intercomparison - Pilot Project 2, Available at http://www.wmo.int/pages/prog/sat/ meetings/documents/IPET-SUP-3_Doc_07-01-02_SCOPE-NWC-PP2.pdf (last access: 28 January 2021), 2017. 

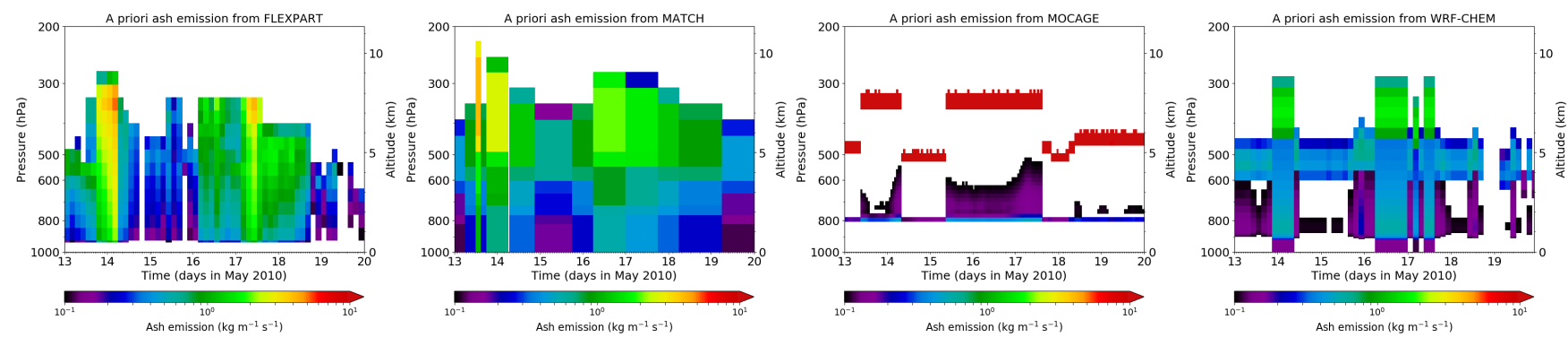

Figure 1. A priori source terms used for FLEXPART, MATCH, MOCAGE, and WRF-Chem (from left to right). The source terms of fine ash are expressed in $\mathrm{kg} \mathrm{m}^{-1} \mathrm{~s}^{-1}$ and are shown as a function of time and height.
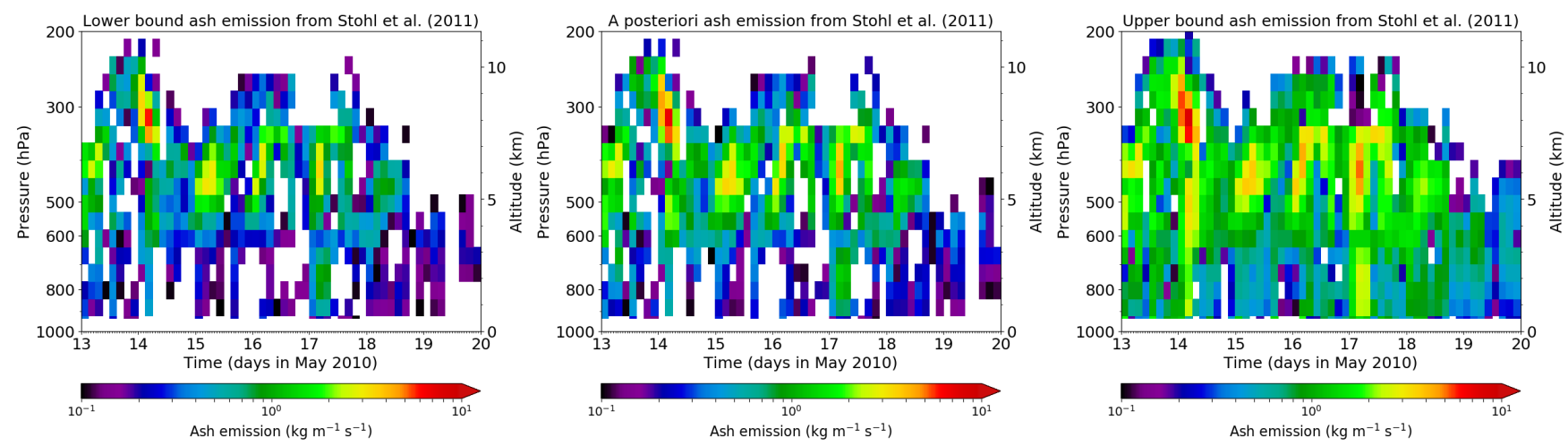

Figure 2. A posteriori source terms derived from Stohl et al. (2011): lower bound, best estimate, and upper bound (from left to right). The source terms of fine ash are expressed in $\mathrm{kg} \mathrm{m}^{-1} \mathrm{~s}^{-1}$ and are shown as a function of time and height. 
https://doi.org/10.5194/nhess-2021-96

Preprint. Discussion started: 9 April 2021

(c) Author(s) 2021. CC BY 4.0 License.
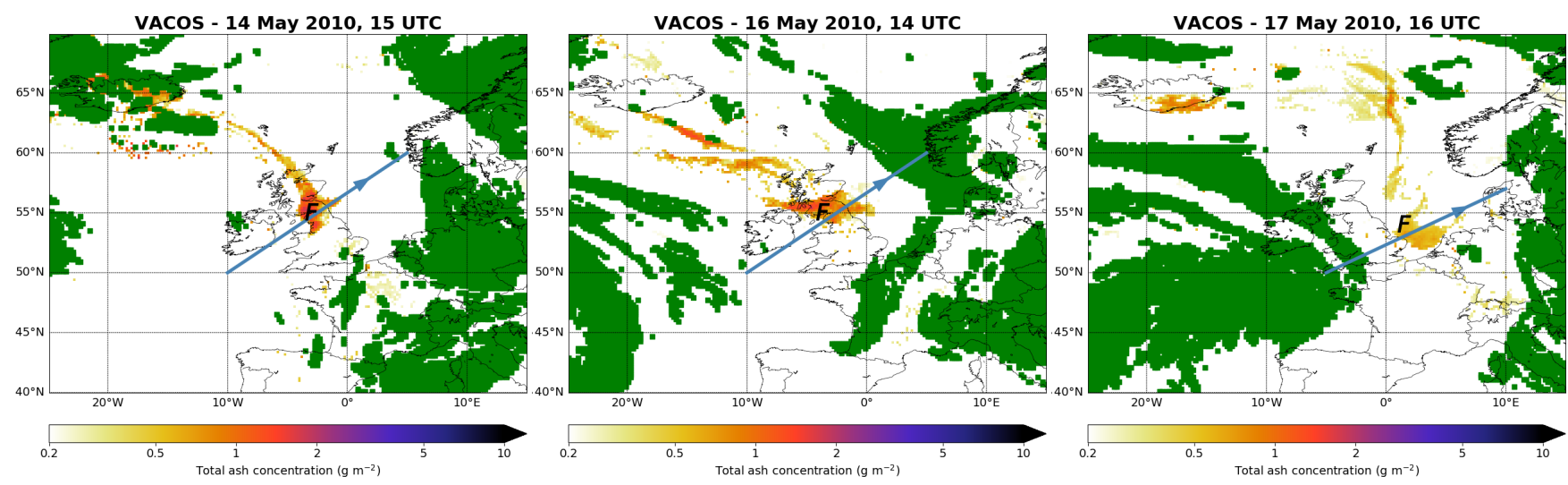

Figure 3. Ash column load retrieved from MSG/SEVIRI by the VACOS algorithm, for different dates (from left to right): 14 May at 15 UTC, 16 May at 14 UTC and 17 May at 16 UTC. The green zones refer to areas where the ash detection was not possible due to the presence of high clouds. The blue lines are the cross sections shown in Fig. 6 and $\boldsymbol{F}$ indicates the region where the FAAM flights made lidar measurements that are used in the article. 

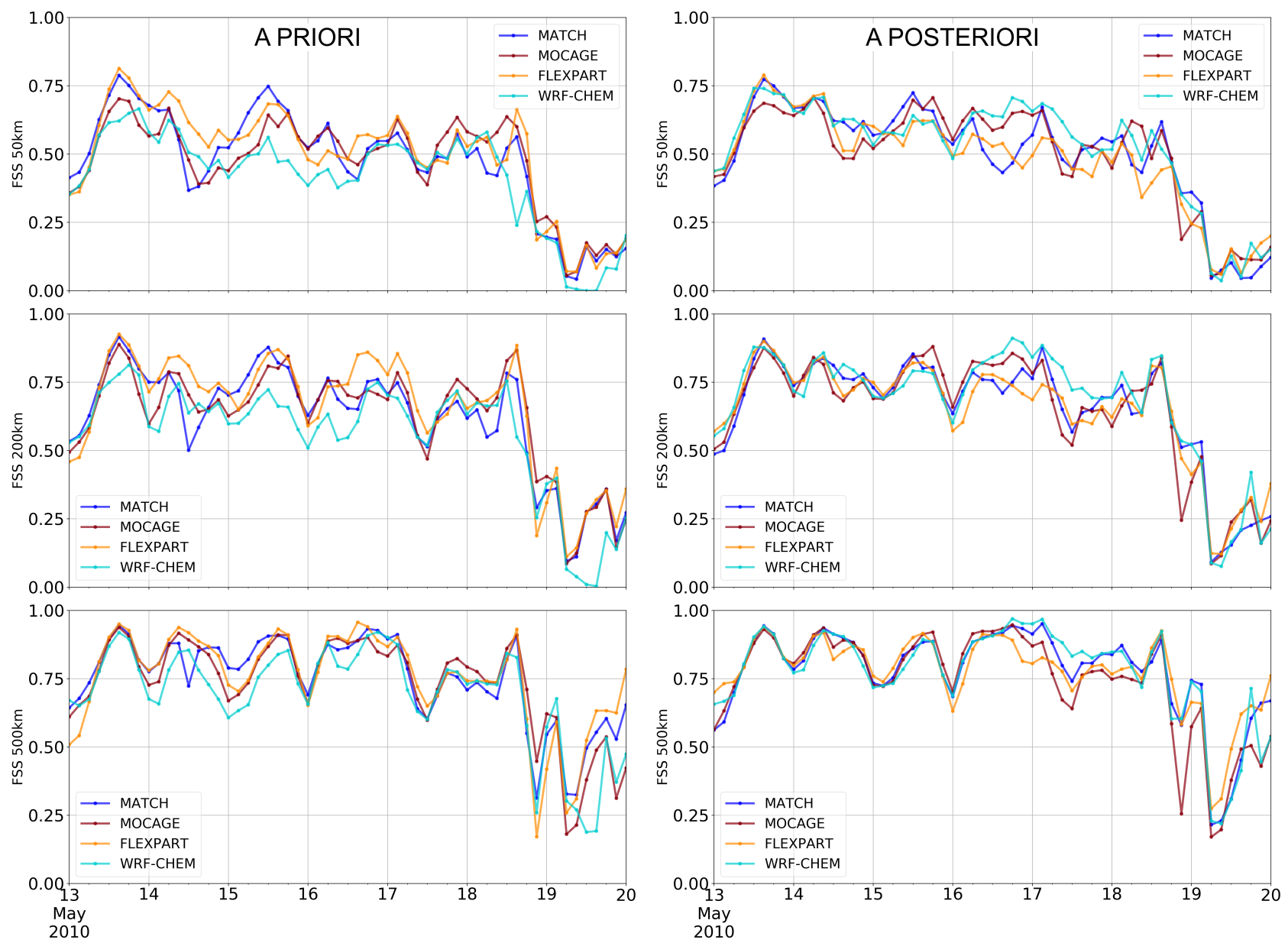

Figure 4. Comparison of the Fraction Skill Score (FSS) for ash location, for the four models with their a priori source terms (left panels) and with the a posteriori source term (right panels). The FSS values are shown for radii of $50 \mathrm{~km}$ (top panels), $200 \mathrm{~km}$ (middle panels), and $500 \mathrm{~km}$ (bottom panels). 
https://doi.org/10.5194/nhess-2021-96

Preprint. Discussion started: 9 April 2021

(c) Author(s) 2021. CC BY 4.0 License.
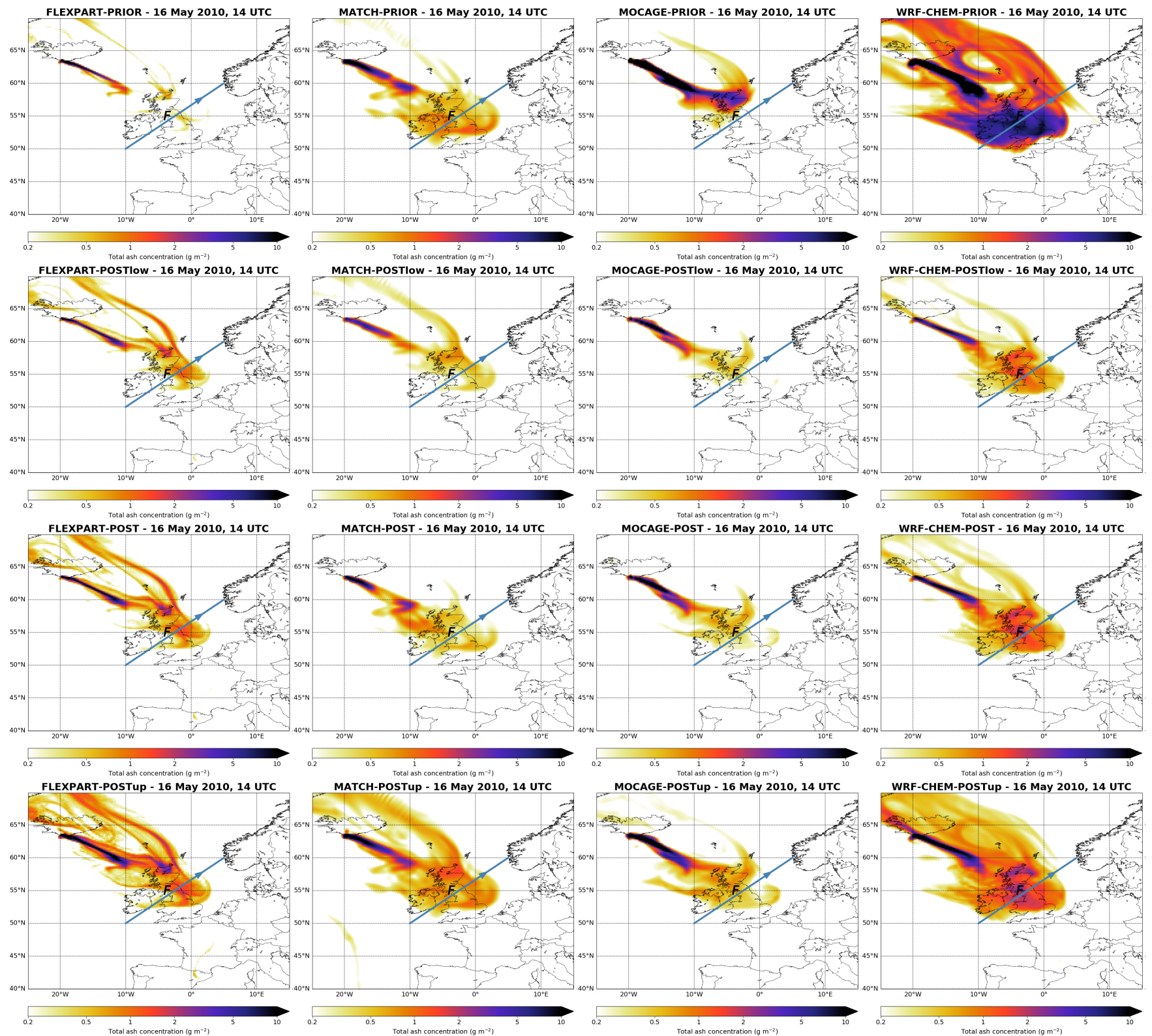

Figure 5. Ash column load on 16 May at 14 UTC for the four models (from left to right: FLEXPART, MATCH, MOCAGE, WRF-Chem). Top panel shows the 4 model outputs with a priori source terms. The 3 other rows show respectively (from top to bottom) the 4 model outputs with the lower limit of the a posteriori source term, the best estimate a posteriori source term, and the upper limit of the a posteriori source term. The model outputs can be compared to the observed values in Fig. 3. The blue lines are the same as in Fig. 3. 
https://doi.org/10.5194/nhess-2021-96

Preprint. Discussion started: 9 April 2021

(c) Author(s) 2021. CC BY 4.0 License.

(c) (i)

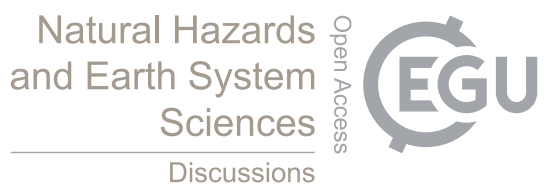

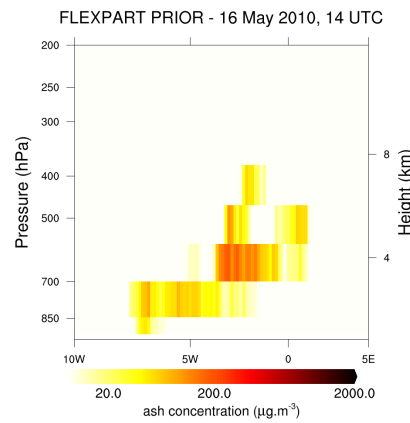
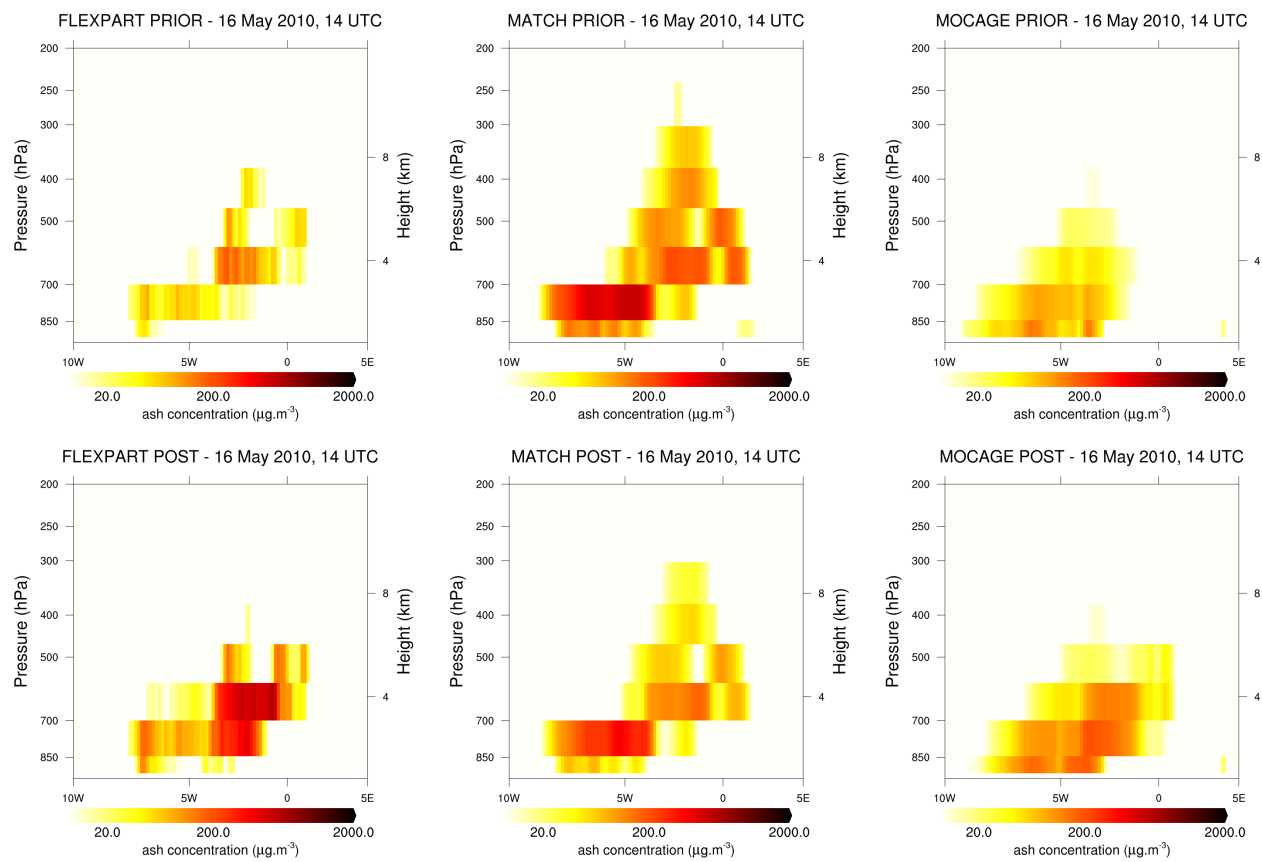
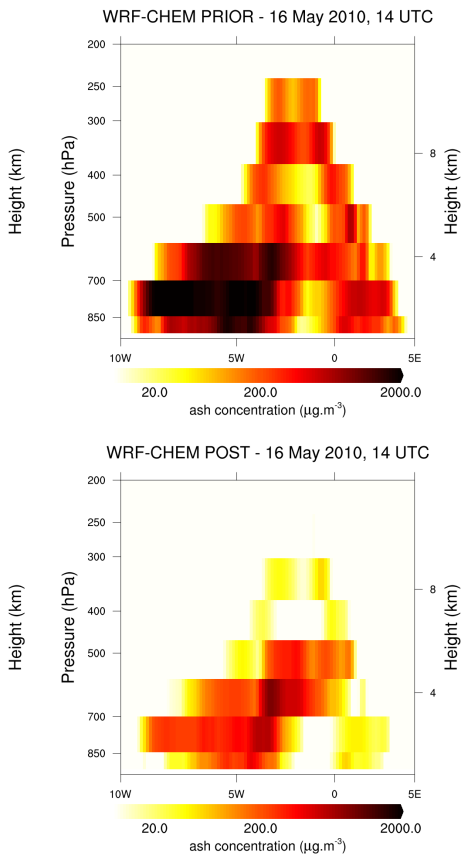

Figure 6. Ash mass concentrations on 16 May 2010 at 14 UTC for the four models (from left to right: FLEXPART, MATCH, MOCAGE, WRF-Chem) with a priori source terms (top) and with a best estimate a posteriori source term (bottom) across the horizontal line shown Fig. 5. 
https://doi.org/10.5194/nhess-2021-96

Preprint. Discussion started: 9 April 2021

(c) Author(s) 2021. CC BY 4.0 License.
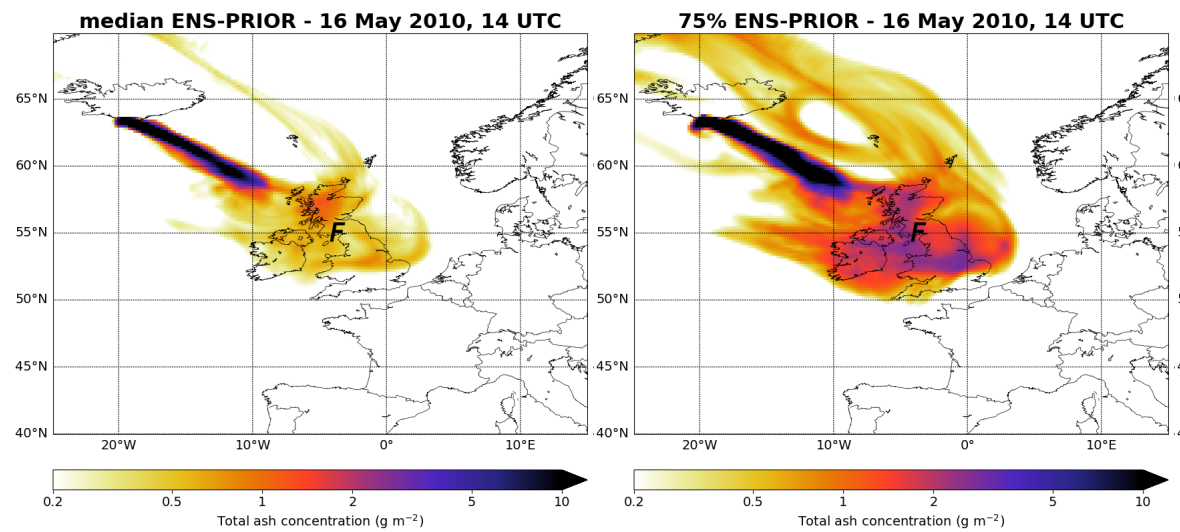

75\% ENS-PRIOR - 16 May 2010, 14 UTC
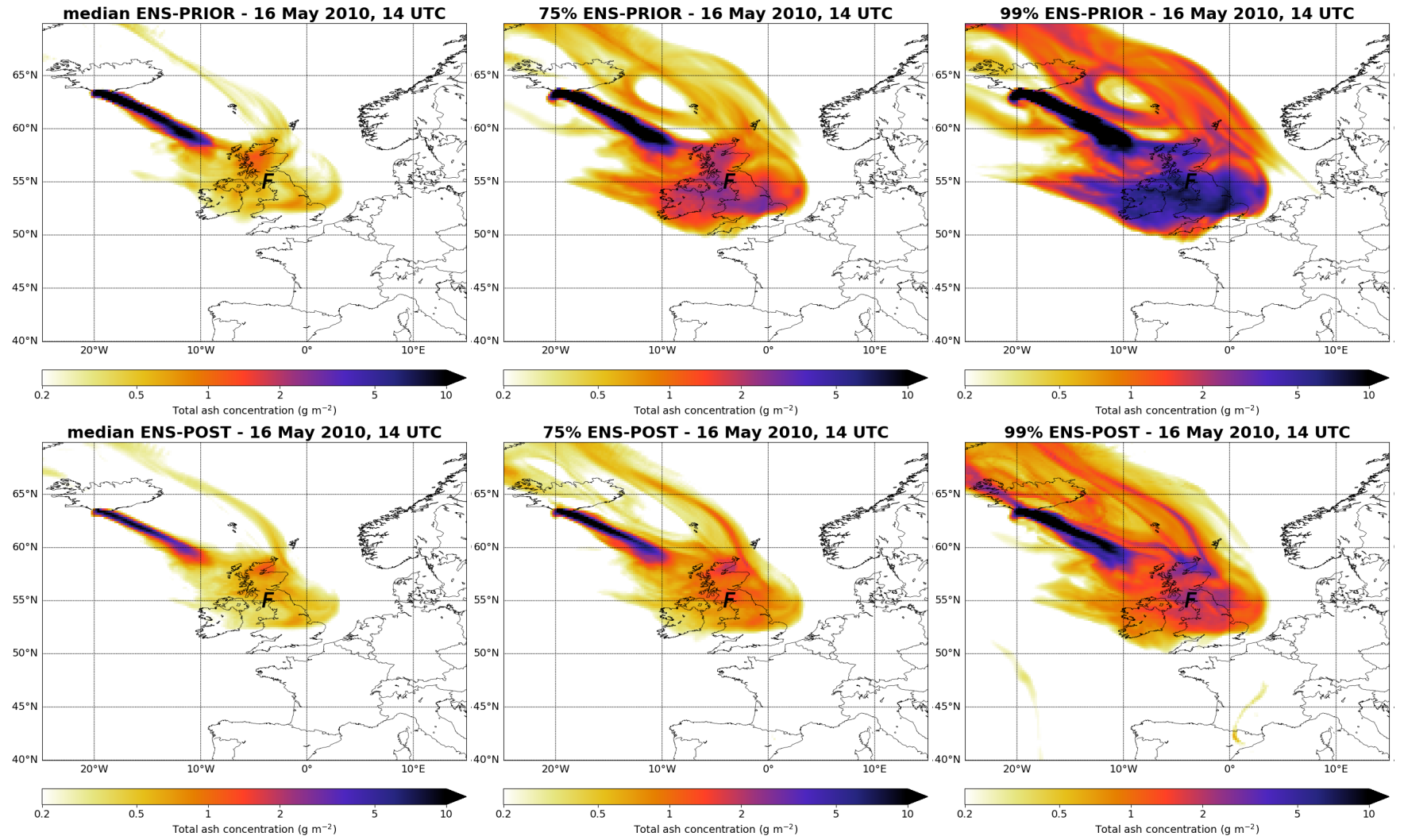

Figure 7. Ash column load on 16 May at 14 UTC for the a priori (top) and for the a posteriori (bottom) ensembles. The ensemble median, $75 \%$ and $99 \%$ are respectively displayed from left to right. 
https://doi.org/10.5194/nhess-2021-96

Preprint. Discussion started: 9 April 2021

(c) Author(s) 2021. CC BY 4.0 License.

(c) (1)
Natural Hazards 웅 and Earth System Sciences

Discussions
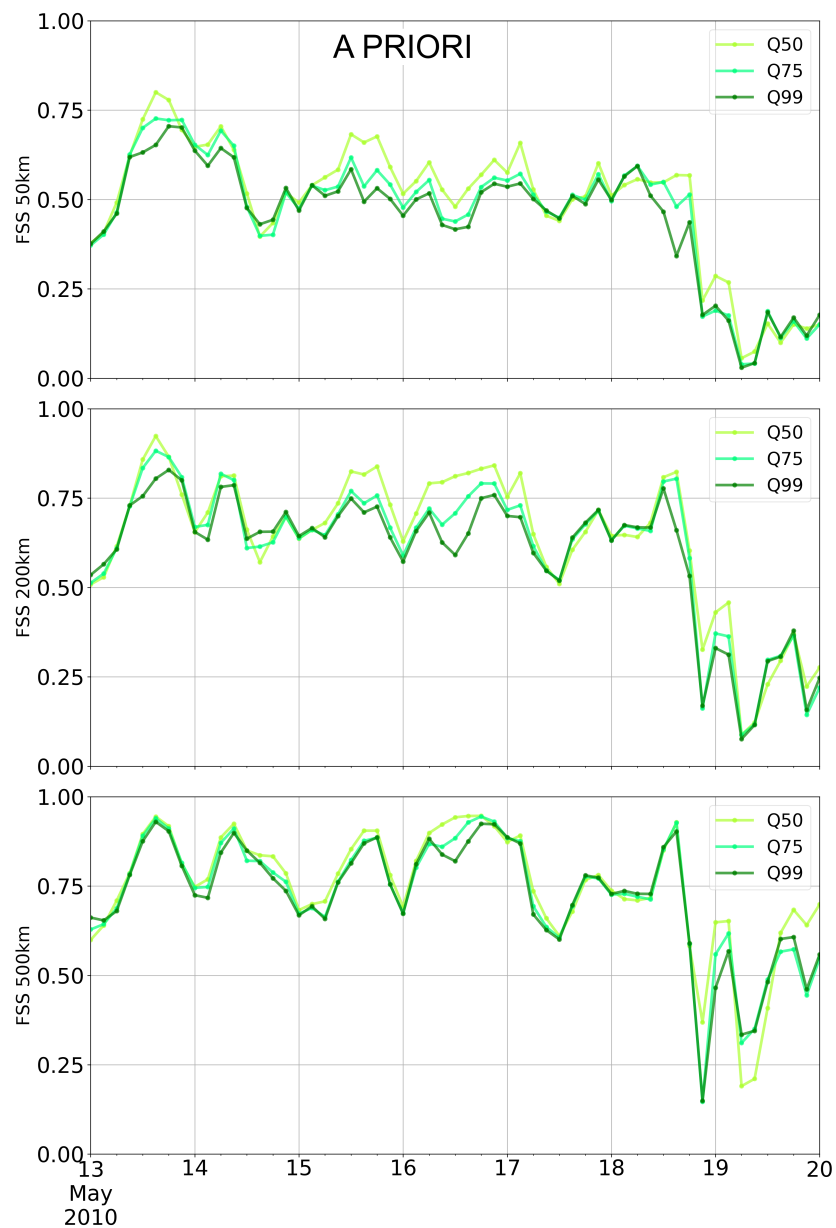

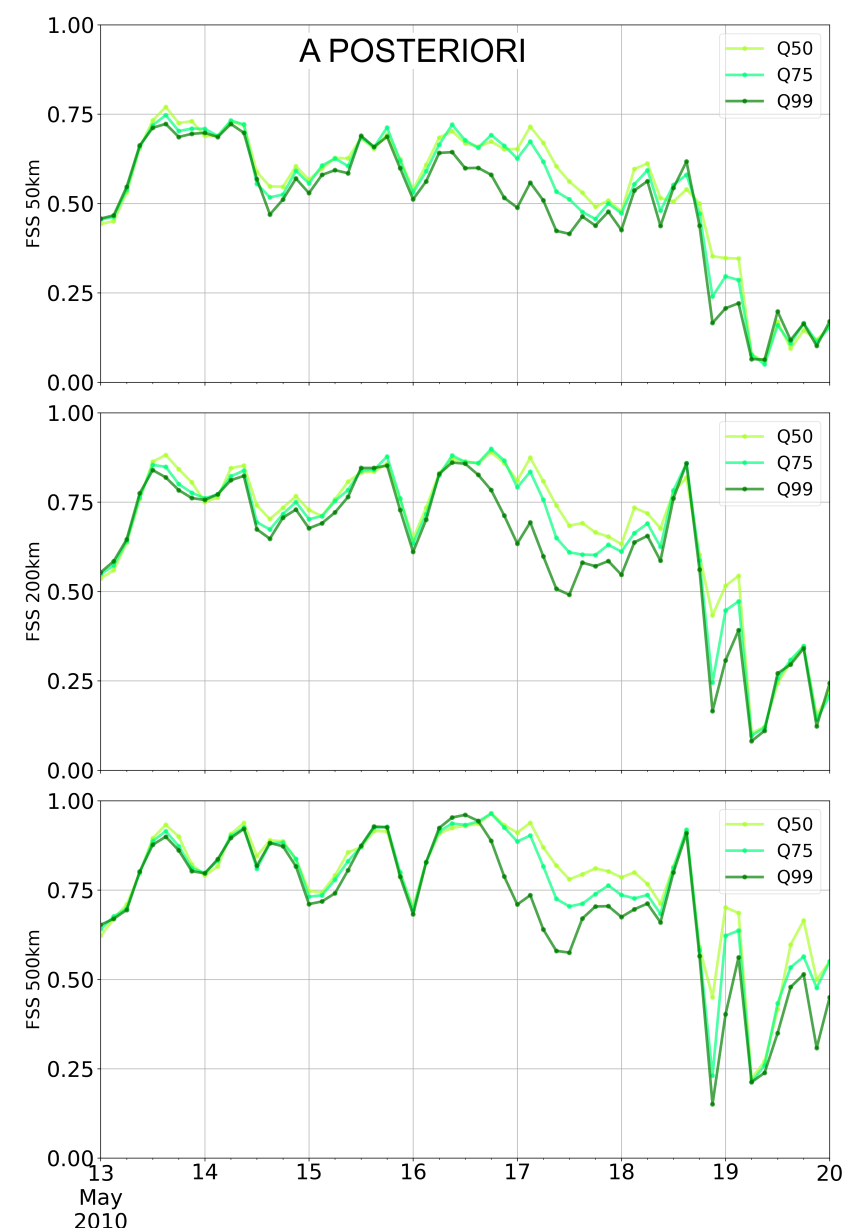

Figure 8. Comparison of the Fraction Skill Score (FSS) of ash column locations, for the ensemble quantiles median, $75 \%$ and $99 \%$ with a priori source terms (left panel) and with a posteriori source term (right panel). The FSS values are shown for radii of $50 \mathrm{~km}$ (top panel), 200 $\mathrm{km}$ (middle panel) and $500 \mathrm{~km}$ (bottom panel). 

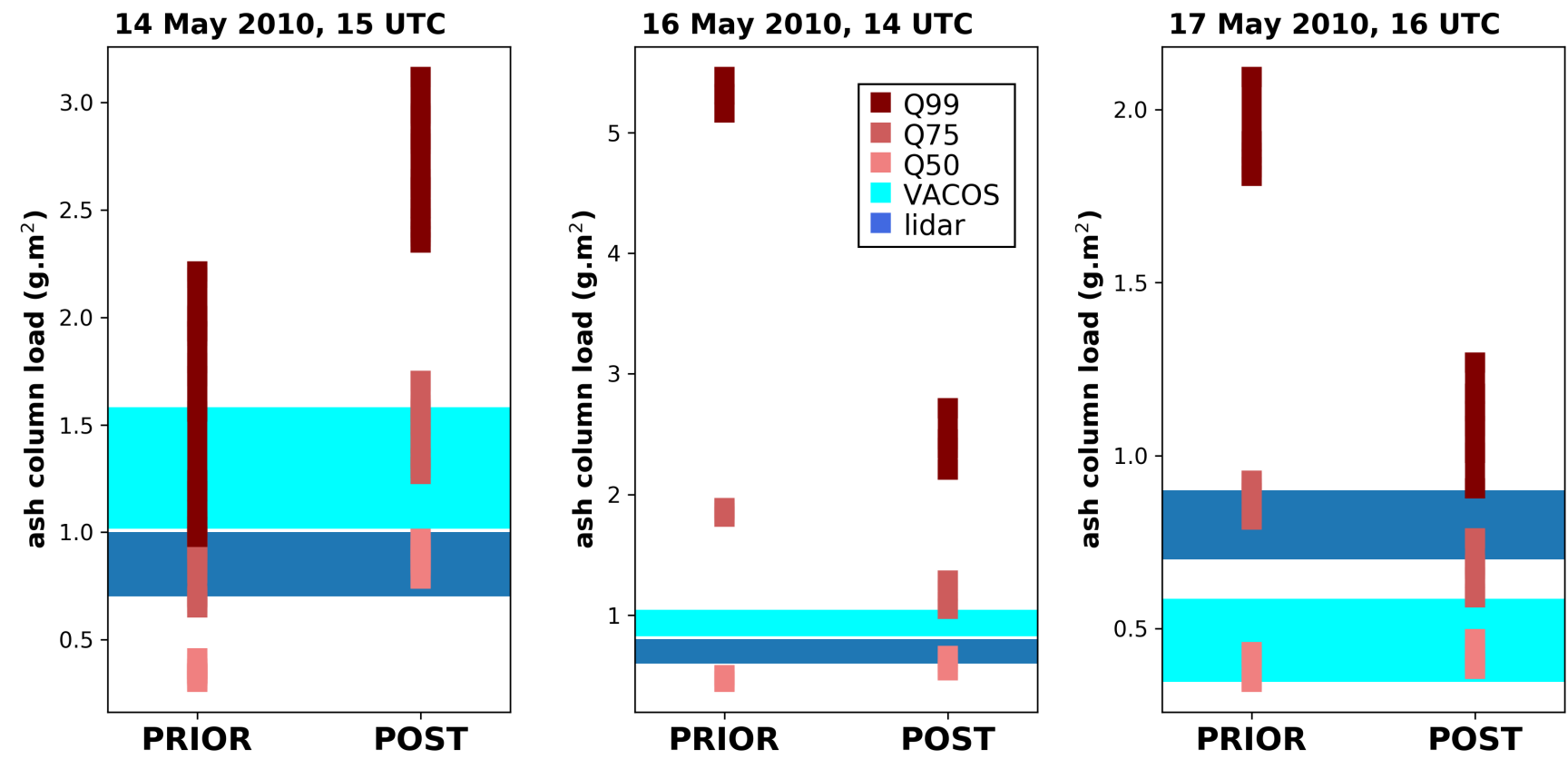

Figure 9. Comparison of ash load (vertical axis, unit $\mathrm{g} \mathrm{m}^{-2}$ ), for the a priori and a posteriori ensemble (abscissa), at the location of lidar measurements shown in Fig. 3, on 14 May at 15 UTC (left), the 16 May at 14 UTC (middle), and 17 May at 16 UTC (right). The range of lidar, resp. VACOS, estimates along the flight track are plotted as blue, resp. light blue, horizontal rectangles. Note that, on these cases, lidar and VACOS values do not overlap. The different quantiles (Q50, Q75, Q99) are plotted as different red tones: the darker the higher the quantiles. For all data, the values of several gridpoints are plotted, that sample the values along the flight track. Note different $y$-axis scales. 


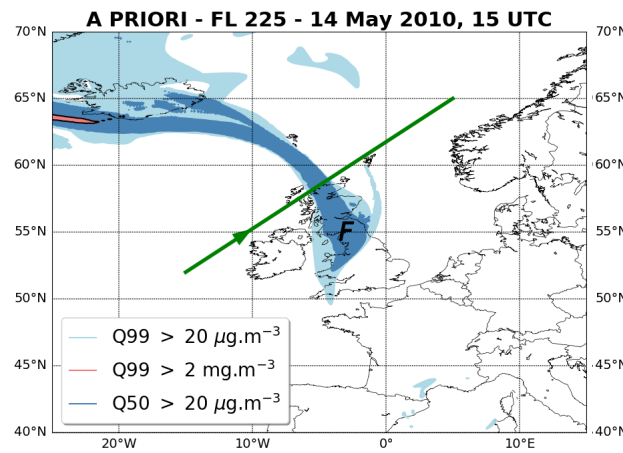

A PRIORI - FL 225 - 16 May 2010, 14 UTC

A PRIORI - FL 175 - 17 May 2010, 16 UTC

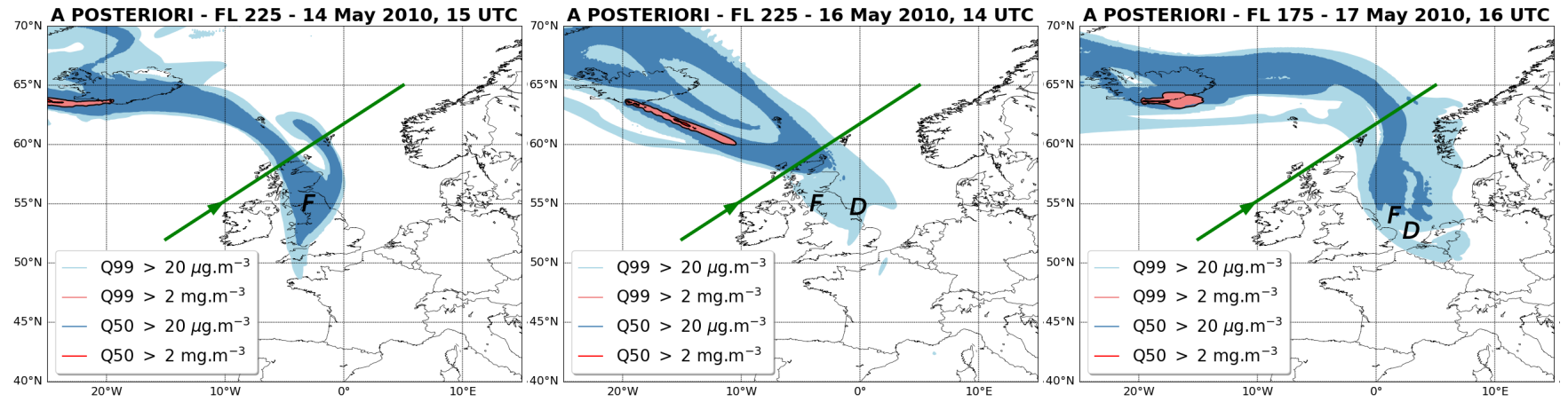

Figure 10. Ash concentrations from the a priori (top panels) and a posteriori (bottom panels) ensemble, at dates and levels where in-situ measurements are available (from left to right: FL225 on 14 May at 15 UTC, FL225 on 16 May at 14 UTC, and FL175 on 17 May at 16 UTC. Blue areas indicate ash concentrations higher than $20 \mu \mathrm{g} \mathrm{m}^{-3}$, with different tone for Q50 and Q99. Red colors refer to concentrations above $2 \mathrm{mg} \mathrm{m}^{-3}$, with different tone for Q50 and Q99. Airplane locations are indicated by the symbols $\boldsymbol{F}$ and $\boldsymbol{D}$, for FAAM and DLR flights, respectively. The green lines refer to the cross sections shown in Fig. 11. 
https://doi.org/10.5194/nhess-2021-96

Preprint. Discussion started: 9 April 2021

(c) Author(s) 2021. CC BY 4.0 License.
Natural Hazards 웅 and Earth System Sciences

Discussions
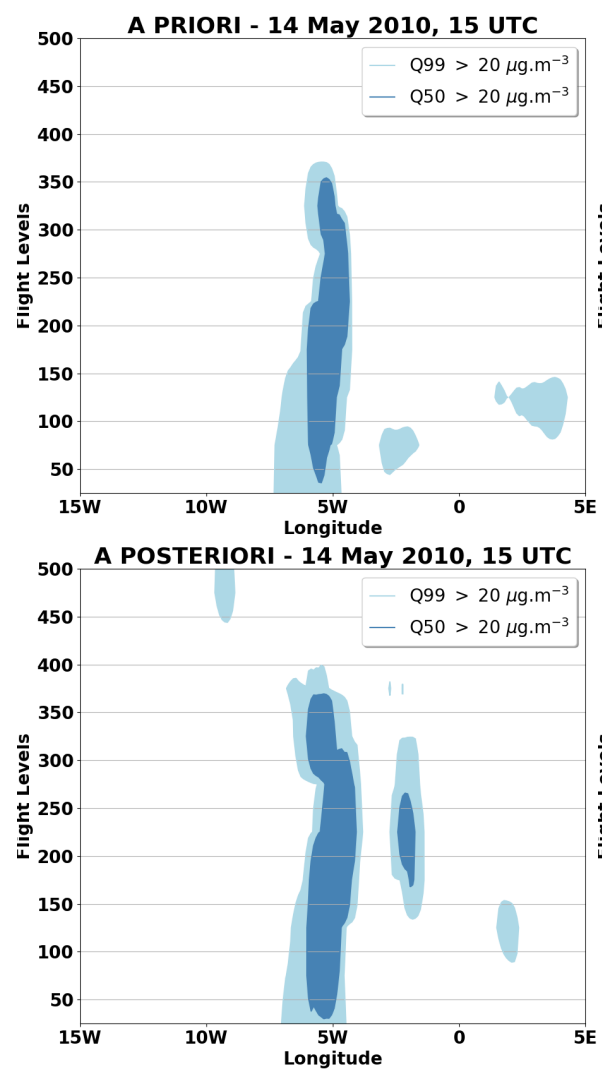

A PRIORI - 16 May 2010, 14 UTC

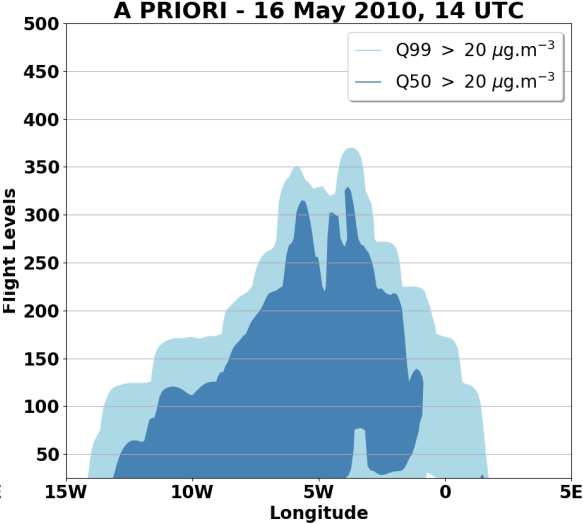

A POSTERIORI - 16 May 2010, 14 UTC

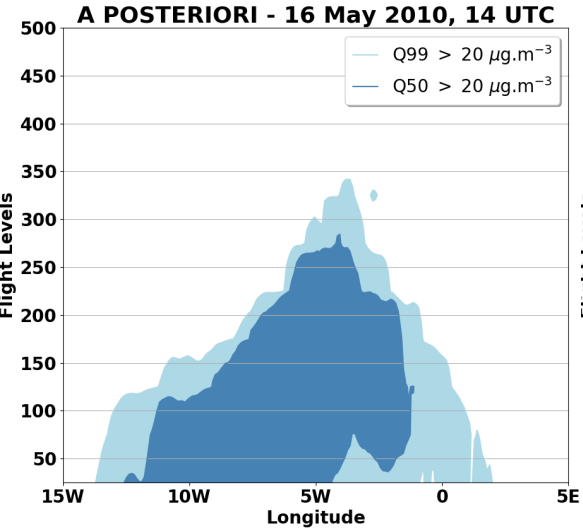

A PRIORI - 17 May 2010, 16 UTC
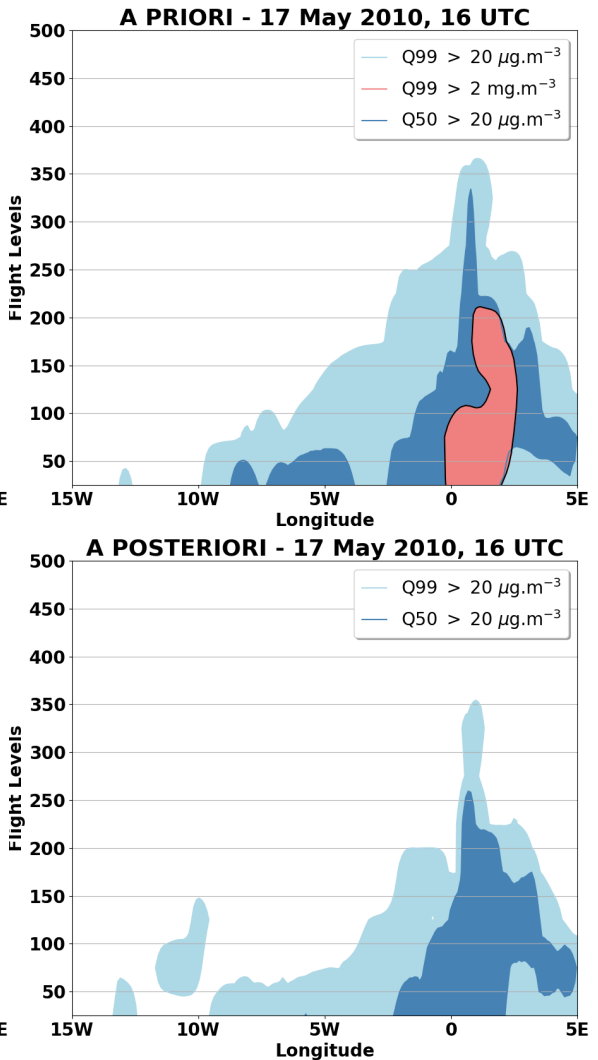

Figure 11. Ash concentrations from the a priori (top panel) and a posteriori (bottom panel) ensemble along the cross-sections shown in Fig. 10. The dates and the color legend are the same as in Fig. 10. 